\title{
Roles of telomeres and telomerase in cancer, and advances in telomerase- targeted therapies
}

\author{
Mohammad A. Jafri', Shakeel A. Ansari', Mohammed H. Alqahtani ${ }^{1}$ and Jerry W. Shay ${ }^{1,2^{*}}$
}

\begin{abstract}
Telomeres maintain genomic integrity in normal cells, and their progressive shortening during successive cell divisions induces chromosomal instability. In the large majority of cancer cells, telomere length is maintained by telomerase. Thus, telomere length and telomerase activity are crucial for cancer initiation and the survival of tumors. Several pathways that regulate telomere length have been identified, and genome-scale studies have helped in mapping genes that are involved in telomere length control. Additionally, genomic screening for recurrent human telomerase gene hTERT promoter mutations and mutations in genes involved in the alternative lengthening of telomeres pathway, such as ATRX and DAXX, has elucidated how these genomic changes contribute to the activation of telomere maintenance mechanisms in cancer cells. Attempts have also been made to develop telomere length- and telomerase-based diagnostic tools and anticancer therapeutics. Recent efforts have revealed key aspects of telomerase assembly, intracellular trafficking and recruitment to telomeres for completing DNA synthesis, which may provide novel targets for the development of anticancer agents. Here, we summarize telomere organization and function and its role in oncogenesis. We also highlight genomic mutations that lead to reactivation of telomerase, and mechanisms of telomerase reconstitution and trafficking that shed light on its function in cancer initiation and tumor development. Additionally, recent advances in the clinical development of telomerase inhibitors, as well as potential novel targets, will be summarized.
\end{abstract}

\section{Background}

Cancer is generally an age-related genetic disease, manifesting only when normal cells accumulate genomic instability over a period of time and acquire the capability of replicative immortality. Telomere attrition during successive cell divisions induces chromosomal instability and contributes significantly to genomic rearrangements that can result in tumorigenesis. Telomeres, repetitive (TTAGGG) DNAprotein complexes at the ends of chromosomes, are crucial for the survival of cancer cells. They are maintained by an enzyme called telomerase in the vast majority of tumors. The mechanisms underlying telomere length (TL) maintenance and telomerase expression involve transcriptional, post-transcriptional and epigenetic regulation, and in-depth understanding of these mechanisms may provide novel

\footnotetext{
* Correspondence: jerry.shay@utsouthwestern.edu

${ }^{1}$ Center of Excellence in Genomic Medicine Research, King Abdulaziz University, Jeddah 21589, Kingdom of Saudi Arabia

${ }^{2}$ Department of Cell Biology, University of Texas Southwestern Medical Center, Dallas, Texas 75390, USA
}

(C) 2016 The Author(s). Open Access This article is distributed under the terms of the Creative Commons Attribution 4.0 International License (http://creativecommons.org/licenses/by/4.0/), which permits unrestricted use, distribution, and reproduction in any medium, provided you give appropriate credit to the original author(s) and the source, provide a link to the Creative Commons license, and indicate if changes were made. The Creative Commons Public Domain Dedication waiver (http://creativecommons.org/publicdomain/zero/1.0/) applies to the data made available in this article, unless otherwise stated. mination of disease prognosis, and the development of therapeutics [1].

Telomeres protect chromosome ends from fusion and from being recognized as sites of DNA damage (Box 1). Dysfunctional telomeres, arising by critical shortening of telomeres in normal somatic cells during progressive cell divisions, elicit DNA damage responses (DDRs) that trigger cellular senescence. Cells that gain oncogenic changes bypass senescence and continue to divide (extended lifespan period) until multiple critically shortened telomeres initiate crisis (a period of complete replicative senescence, chromosome end-to-end fusions, and extensive apoptosis). This leads to breakage-fusion-bridge cycles in which two sister chromatids lacking telomeres fuse together, forming a bridge with a chromatin connection. During anaphase, the sister chromatids are drawn apart owing to movement towards opposite poles, resulting in the formation of uneven derivative chromosomes, leading 


\section{Box 1. Major historical research milestones in telomere and telomerase biology}

Telomeres: Discovered by American geneticist Hermann J. Muller working on Drosophila melanogaster in 1938. He observed that the ends of irradiated chromosomes were resistant to mutagenic $X$-rays and did not undergo deletions or inversions due to the presence of cap-like structures that he called "telomeres" [81].

A crucial role for telomeres in chromosomal integrity: Elucidated by Barbara McClintock in 1941. She described that rupture of the chromosomes resulted in the formation of dicentric chromosomes due to fusion of their ends, and demonstrated that damaged ends of the chromosomes could be restored [82].

Cellular immortality in culture: Alex Carrel, recipient of the 1912 Nobel Prize in physiology, working at the Rockefeller Institute demonstrated that chick heart tissue culture cells can be maintained in long-term cultures by replenishing with fresh culture medium. He hypothesized that the lifespan of cultured tissues could be extended indefinitely and that the tissues should intrinsically be able to maintain permanent life in vitro under ideal culture conditions. Later, Carrel's associates showed a continuous culture of chick heart cells from 1912 to 1946 , and the idea of cell immortality as an intrinsic property was widely accepted by the scientific community. However, it was then discovered that the use of chick embryo extract to culture these cells was actually re-seeding fetal cells and thus the immortality reported by the Carrel laboratory has been largely discounted.

The concept of normal cell immortality challenged: Leonard Hayflick, in 1961 at the Wistar Institute, demonstrated that normal human fetal cells in culture could divide only 40 to 60 times, and after that they underwent aging at the cellular level (then called phase III and now replicative senescence) [83].

End replication problem: In 1971, James Watson, the co-discoverer of the DNA double helix, suggested that there was an "end replication problem" due to the mechanism governing semi-conservative DNA replication. Watson predicted, based on the asymmetry of how linear duplex DNA is copied, that each cell division would result in the extreme termini of chromosomes being lost. This would be incompatible with long-term maintenance of the genome owing to progressive chromosome shortening with each replication cycle, eventually reaching a critical point leading to cell senescence or death. In addition, he postulated the existence of a protective mechanism to prevent chromosomal shortening [84].

Hypothesis about cellular aging: Also in 1971, Alexsey Olovnikov, a Russian scientist, hypothesized that there could be a problem with the ends of chromosomes. He postulated that progressive shortening of the telomere would eventually run into essential genes, leading to cellular aging and perhaps contributing to human aging [85].

Tetrahymena thermophila telomeres tandem repeat sequences: In 1978, Elizabeth Blackburn and Joseph Gall carried out sequencing experiments for the DNA of the Tetrahymena thermophila minichromosome and reported that telomeres contained 20-70 tandem copies of a simple hexanucleotide with the sequence 5'-CCCCAA-3' on one strand and 5'-TTGGGG-3' on the complementary strand [86].

Telomerase: Blackburn and Carol Greider, at Berkeley in 1985, identified an enzymatic activity capable of extending telomeric sequences. The enzyme was named terminal telomere transferase but is now known as telomerase [87]. Along with Jack W. Szostak they received the 2009 Nobel Prize for their discovery that telomeres are protected from progressive shortening by the enzyme telomerase.

Human telomerase: Gregg Morin, in 1989 at Yale University, was the first to report telomerase activity in crude HeLa cell extracts. He also demonstrated that human telomeres consisted of the repeated sequence TTAGGG [88]. In 1994, Jerry Shay and colleagues showed telomerase activity in $~ 90 \%$ of human cancers and cell lines [89], and in 1998 the same team demonstrated that introduction of hTERT (the catalytic protein reverse transcriptase component of telomerase) into normal human cells was sufficient to immortalize cells [90].

to genomic instability. The period of crisis results in extensive cell death. However, certain rare cells escape crisis and maintain stable but usually shortened telomere lengths for continued cell growth, eventually progressing to a malignant phenotype. Cancer cells achieve proliferative immortality by activating or upregulating the normally silent human TERT gene ( $h T E R T)$ that encodes telomerase, a protein with reverse transcriptase activity that complexes with other proteins and a functional RNA (encoded by $h T R$, also called $h T E R C$ ) to make a ribonucleoprotein enzyme complex. Rarely, another DNA recombination mechanism termed alternative lengthening of telomeres (ALT) reverses telomere attrition in order to bypass senescence. Although $h T E R T$ is usually silenced in almost all somatic cells, it is significantly expressed in $\sim 90 \%$ of human cancers. The details of the underlying mechanisms of hTERT activation are still being elucidated, but they mainly include mutations in the $h T E R T$ promoter, alterations in alternative splicing of hTERT pre-mRNA, hTERT amplification, epigenetic changes, and/or disruption of telomere position effect (TPE) machinery [2]. 
Recent reports have implicated two cancer-specific hTERT promoter mutations (mainly $\mathrm{C} \mathrm{T}$ transitions) in the activation of telomerase in cancer cells $[3,4]$. These mutations, which are located either -124 base pairs (bp) or -146 bp upstream from the TERT translation start site $[5,6]$, have been found to be associated with increased telomerase activity [7]. Therefore, molecular mechanisms that regulate $h T E R T$ expression and telomerase assembly have been subjected to intense investigation. Studies using telomerase inhibition strategies have established that robust $h T E R T$ inhibition can lead to progressive telomere shortening and eventually cancer cell death. Several approaches, including use of small-molecule inhibitors, antisense oligonucleotides, immunotherapy, and G-quadruplex stabilizers have been employed to inhibit telomerase function [8]. Currently, many anti-telomerase therapeutics are being evaluated in clinical trials against a variety of cancer types. The following sections will cover recent developments in the area of telomere and telomerase biology, their implications for understanding mechanisms underlying cancer and for the development of cancer therapies, as well as outstanding questions for the field.

\section{Telomeres: organization, function and association with cancer}

Recent studies have significantly contributed to our understanding of telomere organization in the nucleus, telomere profiling for risk stratification, and the signaling pathways that mediate modulation of telomere structural component proteins or factors to regulate gene transcription [9]. Telomeres consist of a capping structure, which is a specialized nucleoprotein structure consisting of DNA and shelterin protein complexes. Telomeric DNA contains a variable number of G-rich, non-coding, tandem repeats (10-15 kilobases $(\mathrm{kb})$ long in humans at birth) of doublestranded DNA sequence, $5^{\prime}$-(TTAGGG) ${ }_{n}-3$ ', followed by a terminal 3' G-rich single-stranded overhang (150-200 nucleotide long). The 3' G-rich overhang facilitates telomeric DNA in forming a higher-order structure in which the $3^{\prime}$ single-stranded overhang folds back and invades the homologous double-stranded TTAGGG region, forming a telomeric loop (T-loop) that provides 3 '-end protection by sequestering it from recognition by the DDR machinery [10]. The proteins associated with telomeres are called the shelterin complex, which consists of three core shelterin subunits, TRF1 and TRF2, which directly recognize and bind duplex TTAGGG repeats, and POT1, which recognizes and binds single-stranded TTAGGG overhangs. These three proteins are interconnected by three additional shelterin proteins, TIN2, TPP1 and RAP1, forming a complex that enables DDR surveillance machinery to distinguish telomere DNA from sites of genomic DNA damage (Fig. 1). The shelterin complex performs critical and distinct functions that ensure telomere stability. For example, TRF2 is required for T-loop formation and maintenance of ATM-mediated DDR suppression and repression from non-homologous end joining [11]. TRF1 has a central role in controlling replication of telomeric

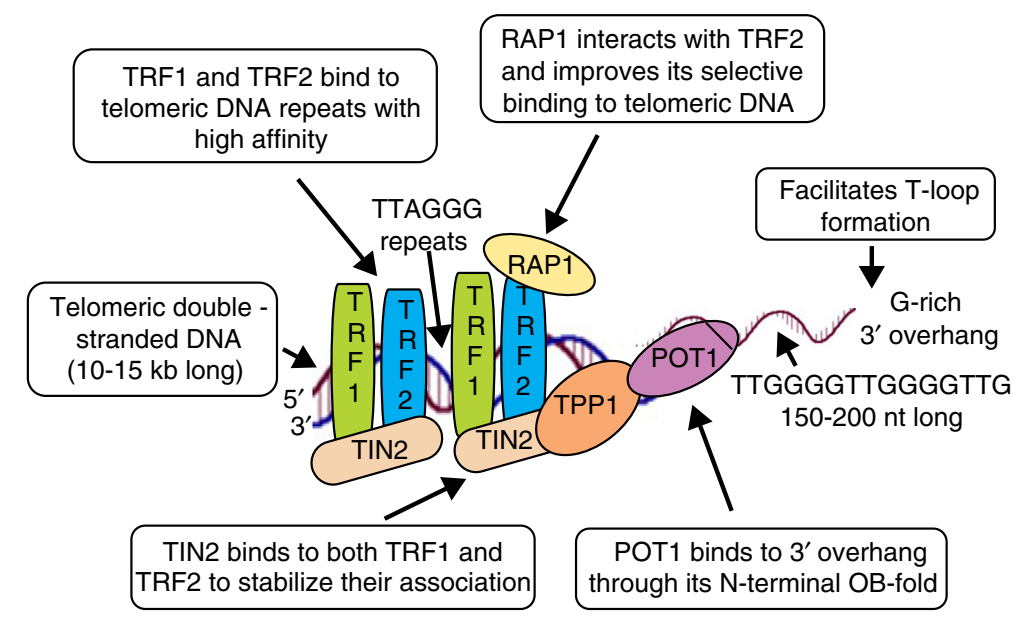

Fig. 1 Schematic representation of telomeric DNA and components of the shelterin complex. Telomeres comprise a specialized nucleoproteincapping structure consisting of DNA and shelterin protein complexes. Telomeric DNA contains a variable number of G-rich, non-coding, tandem repeats of the double-stranded DNA sequence 5'-(TTAGGG) $n_{n}-3$ ', followed by a terminal 3' G-rich single-stranded overhang (150-200 nucleotides (nt) long). The $3^{\prime}$ G-rich overhang facilitates telomeric DNA in forming a higher-order structure in which the $3^{\prime}$ single-stranded overhang folds back and invades the homologous double-stranded TTAGGG region, forming a telomeric loop (T-loop) that provides 3 '-end protection by sequestering it from recognition by the DNA damage response machinery. The proteins associated with telomeres form the shelterin complex, which consists of three core shelterin subunits, TRF1 and TRF2, which directly recognize and bind duplex TTAGGG repeats, and POT1, which recognizes and binds single-stranded TTAGGG overhangs. These three proteins are interconnected by three additional shelterin proteins, TIN2, TPP1 and RAP1, forming a complex that enables the DNA damage response surveillance machinery to distinguish telomere DNA from sites of genomic DNA damage 
DNA [12] while POT1 associates with TPP1 to bind the single-stranded 3' overhang and repress ATR-mediated DDR by preventing the recruitment of replication protein A (RPA) [13]. TIN2 is essential to the overall integrity of the shelterin complex as it links the TPP1/POT1 heterodimer to TRF1 and TRF2, and stabilizes TRF1 and TRF2 associations with telomeric DNA $[14,15]$. RAP1 interacts with TRF2 and improves its selective binding to telomeric DNA [16].

Apart from DNA end protection, telomeres also perform other important functions such as regulation of gene expression through transcriptional silencing of genes located close to the telomeres, called TPE [17], or located at long distances from telomeres, termed TPE over long distances (TPE-OLD) [18]. The function of telomeres is tightly regulated and depends on a minimal length of telomeric repeats and the functionality of the associated shelterin protein complexes. In addition, higher-order DNA conformations, such as the T-loop and G-quadruplexes (G-rich fourstranded non-helical structures) are thought to contribute to normal telomere function. Moreover, telomeric chromatin has an important role in telomere maintenance, signaling and regulation of telomere function, but many of the precise structures and molecular mechanisms of human telomeric chromatin are not well understood. However, telomeric regions contain telomeric repeat-containing RNA (TERRA), a long non-coding RNA that is transcribed from telomeric DNA by RNA polymerase II [19]. TERRA has been implicated in telomerase regulation, organization of heterochromatin at telomeres, regulation of gene expression, and in DDR triggered by dysfunctional telomeres [19]. The mammalian cell lines harboring active ALT have higher TERRA levels compared with telomerase-positive cells [20]. However, the exact role of TERRA in activation of the ALT mechanism is not clear [21].

TL is critically important in normal cells, and telomere shortening can-in combination with other oncogenic changes-promote genome instability, potentially stimulating initiation of the early stages of cancer. In humans, the distribution of TL among different chromosome arms is heterogeneous. TL reduces at a rate of 50 $150 \mathrm{bp}$ at each cell division in human somatic cells in cell culture. Consequently, individual telomere shortening rates may be different in different cell lineages. The time point at which any chromosome end will become uncapped depends on the specific TL shortening rate in each cell type or tissue. Thus, the shortest telomere is critically important for cell viability and chromosomal stability as it may be a sole contributor to the senescence onset signal [22]. There are two critically important barriers that prevent cell immortalization and ultimately malignant transformation: replicative senescence and crisis [23]. The period of cellular senescence, also known as mortality stage 1 (M1), is characterized by inhibition of cellular proliferation, probably due to the uncapping of one or a few shortened telomeres. In the presence of cancer-initiating changes, M1 can be bypassed, providing an extended cell division period. However, during this phase additional telomeres become very short and these "marked" telomeres result in a new dysfunctional state, termed crisis (or M2 crisis). M2 is a period in which signals to undergo replicative senescence and signals for cells to continue to divide are balanced. This eventually results in chromosome end-to-end fusions and extensive cell death (apoptosis) [24]. However, a rare clone (1 in 100,000 to 1 in 10 million cells) can progress towards the acquisition of cell immortality [25]. At this point, a mechanism must be engaged to maintain these very short telomeres, and this occurs by either increasing or reactivating telomerase expression, or by acquiring a much rarer telomerase-independent ALT mechanism, thus bypassing crisis and ultimately leading to cell immortalization [26] (Fig. 2).

Although telomerase maintains telomere length in the majority of cancer cells, the ALT mechanism is also employed by $10-15 \%$ of tumors [27]. The ALT pathway utilizes a homologous recombination-based DNA replication mechanism to extend telomere length. The activation of the ALT mechanism is thought to involve loss of chromatin-remodeling factors such as ATRX and DAXX, resulting in reduced compaction of telomeric chromatin, which leads to the production of altered telomeric DNA sequences and activation of a telomerespecific DDR pathway $[28,29]$, which in turn stimulates homology-directed synthesis of telomeric DNA. Recently, Flynn and colleagues [30] reported that inhibition of the protein kinase ATR disrupts the ALT mechanism in ALT-positive cancer cells, resulting in cell death. This suggests that ATR inhibitors may be a useful therapeutic intervention for ALT-harboring tumors.

\section{Telomerase: the key telomere length maintenance mechanism}

Telomerase is a large ribonucleoprotein complex responsible for progressive synthesis of telomeric DNA repeats (TTAGGG) at the 3' ends of linear chromosomes, thereby reversing the loss of DNA from each round of replication. Telomerase is a reverse transcriptase that consists of a catalytic protein subunit called telomerase reverse transcriptase (TERT), encoded by the $h T E R T$ gene in humans that is positioned at chromosome $5 \mathrm{p} 15.33$, and an essential RNA component known as human telomerase RNA (hTR) or human telomerase RNA component (hTERC), encoded by the $h T E R C$ gene found on chromosomal region 3q26. hTR acts as a template (carries sequence complementary to one or more copies of telomeric repeats) for the synthesis of telomere DNA, and is also involved in the catalysis, localization and assembly of the 


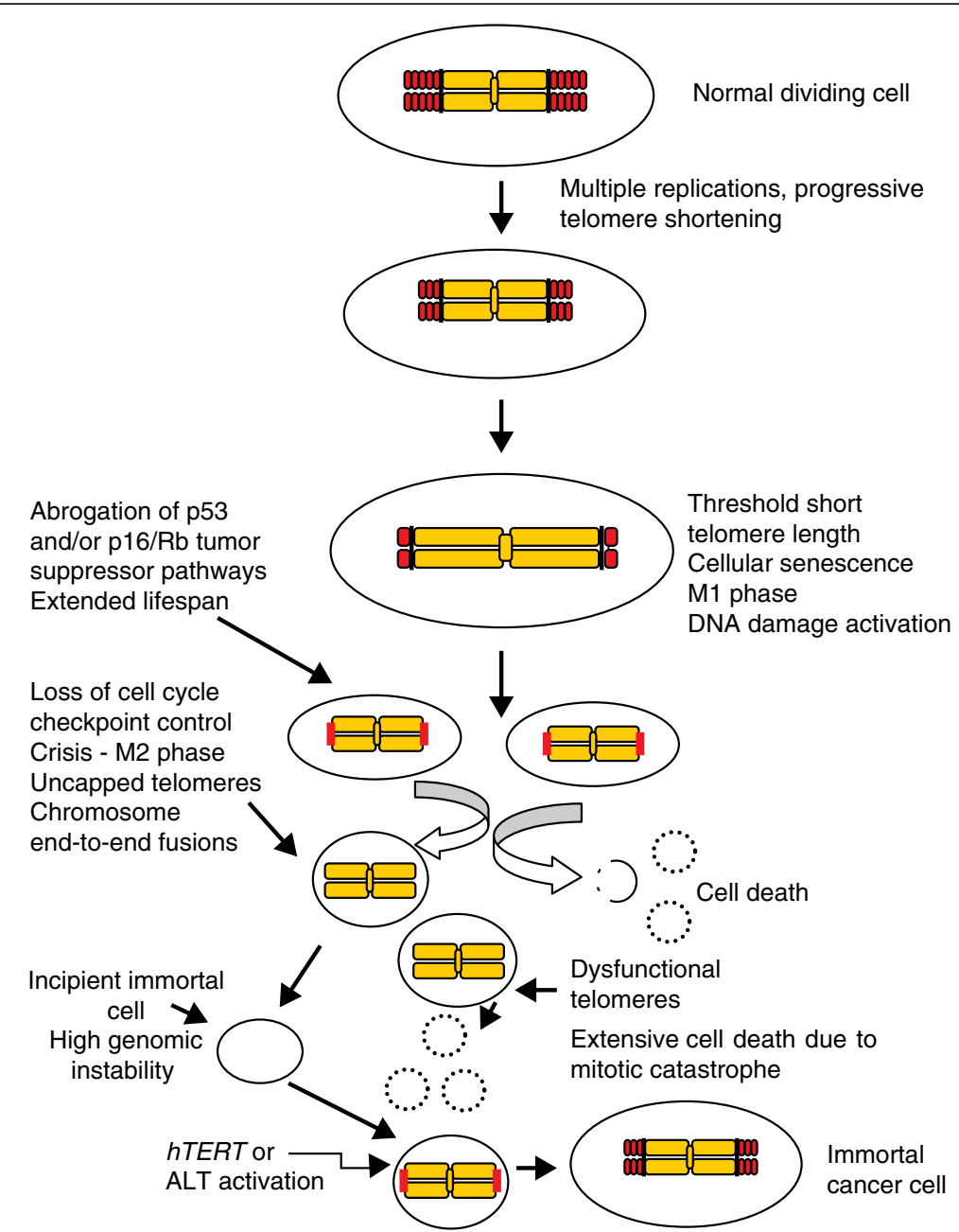

Fig. 2 Cellular senescence and crisis. Telomeres protect chromosome ends from undergoing fusions and recombination by masking telomeric DNA with shelterin protein protective caps, preventing the ends from being recognized by the DNA damage surveillance pathways. Telomere shortening is a natural consequence of cell division due to the "end replication problem" whereby lagging strand DNA synthesis cannot be completed all the way to the very end, and increased cell divisions lead to critically shortened telomeres which elicit DNA damage responses that trigger cellular senescence. In the cells undergoing replicative senescence, the p53 and p16-RB pathways are often activated leading to essentially irreversible growth arrest. Cells that gain additional oncogenic changes (p53 loss) can bypass senescence and continue to divide until multiple critically shortened telomeres initiate crisis, a period of increased chromosome end-to-end fusions and extensive cell death. Only a rare human cell (one in $10^{5}$ to $10^{7}$ ) can engage a mechanism to bypass crisis and become immortal. This is almost universally accomplished by the upregulation or reactivation of telomerase. A rarer telomerase negative immortalization pathway, termed ALT (alternative lengthening of telomeres), involves DNA recombination to maintain telomeres

telomerase holoenzyme [31]. Recent studies have reported that, in addition to TL maintenance, telomerase is also involved in gene expression regulation, cell proliferation, apoptosis, WNT/ $\beta$-catenin signaling, NF-kB signaling, MYC-driven oncogenesis, DDR, cell adhesion and migration, and epithelial-mesenchymal transition [32-35]. All these activities of telomerase are thought to contribute significantly to the process of oncogenesis.

TL maintenance by telomerase is a complex multistep process that involves a series of molecular events including hTERT protein transport and trafficking into the nucleus, hTR and hTERT assembly with accessory components in the nucleus, and recruitment to telomeres at the appropriate time during DNA replication. It has been reported that at least hTERT and hTR are essential for the in vitro reverse transcriptase activity of the human telomerase enzyme [36]. However, under in vivo conditions the telomerase holoenzyme also contains four additional proteins-dyskerin, NHP2, NOP10 and GAR1 (localization factor)-associated with the H/ACA class of small nucleolar RNAs that play an important role in the process of pseudouridylation during post-transcriptional modification of RNAs. In addition, a WD-repeat-containing protein 79 called TCAB1 binds to the CAB-box sequence within hTR and directs the 
telomerase holoenzyme to localize at Cajal bodies bound to the nucleolus [37]. Numerous additional factors such as the chaperones HSP90 and p23, as well as the ATPases pontin and reptin, have also been observed to bind to the two main subunits of telomerase [38]. Many of these factors are thought to be involved in the assembly of a functional telomerase holoenzyme in vivo but the actual mechanisms by which they interact with telomerase remain poorly understood. One working model of human telomerase biogenesis is that dyskerin, pontin and reptin form a scaffold and create an assembly platform for nascent hTR transcripts. Then, the H/ACA motif-binding complex of dyskerin, NHP2 ribonucleoprotein, NOP10 ribonucleoprotein, a nuclear assembly factor ribonucleoprotein (NAF1) and the telomerase ribonucleoprotein (RNP) particle associate. Next, hTR removes NAF1 and attaches GAR1, leading to the formation of a physiologically stable hTR-H/ACA-RNP complex. The hTR 3'-hairpin CAB-box sequence recruits TCAB1, and finally hTERT binds to two structurally independent hTR domains (CR4/CR5), thus generating the catalytically active telomerase RNP [39]. TCAB1, found in Cajal bodies, binds to the $\mathrm{CAB}$ box of hTR and guides telomerase to the Cajal bodies, where it remains localized for most of the cell cycle, but the physiological significance of this process is not known.

The recruitment of telomerase to telomeres occurs only after the replication fork remodels the protected DNA 3' ends during the $\mathrm{S}$ phase of the cell cycle. It involves protein-protein interactions between the shelterin complex components TPP1 and POT1 and the DAT (dissociates the activities of telomerase) domain of hTERT, a region that differentiates the in vivo functionality of hTERT from its in vitro activity. TPP1 contains an N-terminal oligonucleotide/oligosaccharide-binding (OB)-fold domain that includes a patch of amino acids termed the Tel patch, which directly interacts with the telomerase DAT domain [40]. It also contains a central domain that directly binds to POT1 and a C-terminal domain that associates with TIN2. Thus, interaction between the DAT domain of hTERT and shelterin components ensures correct positioning of telomerase at the 3' end of DNA for synthesis and processivity of telomeric repeats. Telomerase loading onto the telomeres is mediated by SRSF11 (a novel TERCbinding protein), which leads to the stable association of the enzyme with the telomere overhang, and proper positioning of the DNA 3' end at the active site of the enzyme for nucleotide addition [41] (Fig. 3).

\section{The role of telomerase in cancer: TERT promoter mutations and telomerase reactivation}

Telomerase upregulation or reactivation is a critical feature in over $90 \%$ of cancers. However, the mechanisms governing hTERT expression in cancer remain incompletely understood. Therefore, understanding how
hTERT is activated in cancer cells and how it contributes to further progression of the disease continues to be a major area of research.

hTERT is a $40 \mathrm{~kb}$ gene consisting of 15 introns and 16 exons. It is located on the short arm of human chromosome 5 (5p15.33) approximately 1.2 megabases away from the telomere, embedded in a nuclease-resistant chromatin domain [42]. The hTERT promoter is GC rich and lacks both TATA (found in the promoter regions of genes that encode proteins found in both eukaryotes and prokaryotes) and CAAT (which rarely occurs in the promoter region of eukaryotes but is completely absent in prokaryotes) boxes but contains binding sites for multiple transcription factors, suggesting that $h T E R T$ expression is under multiple levels of control and may be regulated by different factors in different cellular contexts.

The $260 \mathrm{bp}$ proximal region designated as the hTERT promoter core is responsible for most of its transcriptional activity. It contains at least five GC boxes (GGGCGG), which are binding sites for the zinc finger transcription factor SP1, and are essential for hTERT promoter activity. Two E-boxes (5'-CACGTG-3'), located at positions -165 and +44 of the nucleotide sequence of $h T E R T$ relative to the transcription start site (TSS), provide binding sites for several enhancer binding proteins such as the MYC/MAX/ MXD1 family and USF1/2. The E-boxes are not only important for $h T E R T$ promoter activation by c-MYC, but also bind to MAD1 and USF1 to mediate hTERT repression. The $h T E R T$ promoter core also contains a single TSS that binds the multifunctional transcription factor TFII-I. The transcription of the $h T E R T$ promoter is regulated by the action of multiple transcription factors and the telomere chromatin environment. However, it remains unsolved how the interplay between transcription factors and the telomere chromatin milieu controls hTERT transcription. Several transcription factors bind to the $h T E R T$ promoter core to activate or repress $h T E R T$ transcription. The transcription factors that upregulate transcription include c-MYC, SP1, E-twenty-six (ETS) family members, NF-kB, AP-2 and HIF-1. Transcription factors such as p53 (also known as TP53; represses transcription in an SP1-dependent manner), MAD (transcription factor involved in a network controlling cell cycle progression), WT1, MZF-2, SIP1 and menin have been shown to downregulate hTERT transcription. Most of the transcription factors that upregulate the telomerase gene are widely expressed and cannot fully account for high levels of hTERT expression and activation during tumorigenesis (Fig. 4).

Recent observations of two highly recurrent mutations at two sites within the core promoter region of hTERT suggest one possible mechanism for the activation of telomerase in cancer cells. These mutations, which occur at -124 bp and -146 bp upstream from the ATG start site, are C T transitions (at positions 1,295,228 (C228T) and 
1,295,250 (C250T) on chromosome 5), and each mutation generates an identical 11 bp nucleotide stretch (5'CCCCTTCCGGG-3') containing a consensus binding motif $(\mathrm{GGA}(\mathrm{A} / \mathrm{T}))$ for ETS transcription factors that can function as transcriptional repressor, activator or both to regulate telomerase expression [3, 4]. However, the molecular mechanisms of telomerase activation by ETS are not clearly understood. It has recently been reported that epidermal growth factor (EGF)-mediated activation of telomerase activity in lung cancer is associated with direct binding of ETS-2 to the $h T E R T$ promoter [43]. The recurrent $h T E R T$ promoter mutations were first reported as germline mutations from a family of melanoma patients and were later seen through genome sequencing of sporadic melanoma (in $>74 \%$ melanomas) and a number of cell lines across numerous cancer types and were associated with increased $h T E R T$ promoter activity $[3,4]$. These mutations occur in approximately $70 \%$ of melanomas, $80-90 \%$ of glioblastomas, $60 \%$ of hepatocellular carcinomas, $60 \%$ of bladder cancers, $70 \%$ of basal cell carcinomas, $50 \%$ of cutaneous squamous cell carcinomas, up to $30 \%$ of thyroid cancers and approximately $72 \%$ of oligodendrogliomas [4, $6,44,45]$.

Additionally, a less frequent hTERT promoter mutation, -57 bp upstream from the ATG start site, resulting in an $\mathrm{A}>\mathrm{C}$ transition, and other less frequent but recurrent mutations in cancer are found on chromosome 5 at the following positions: 1,295,228 C>A; 1,295,248$1,295,243 \mathrm{CC}>\mathrm{TT}$; and 1,295,161 A>C [46]. However, when these mutations $(-57 \mathrm{~A}>\mathrm{C},-124 \mathrm{C}>\mathrm{T},-146 \mathrm{C}>\mathrm{T})$ are introduced into tumor cells (A375 melanoma cells, UAGCC-62 melanoma cells, T24 bladder cancer cells) using a luciferase reporter construct, only a $\sim 1.5$ - to 2 -fold increase in $h T E R T$ transcription occurs [4, 45, 47]. Similarly, Huang and colleagues [48] also demonstrated that hTERT promoter mutations C228T and C250T caused a 2.8-fold to 5.3-fold increase in transcription (using a luciferase reporter assay in U87-MG cells) and telomerase activation using the telomere repeat amplification protocol (TRAP) assay in both xenografts and primary tumor tissues. It is not clear whether the observed enhanced $h T E R T$ transcription and increased level of $h T E R T$ mRNA are

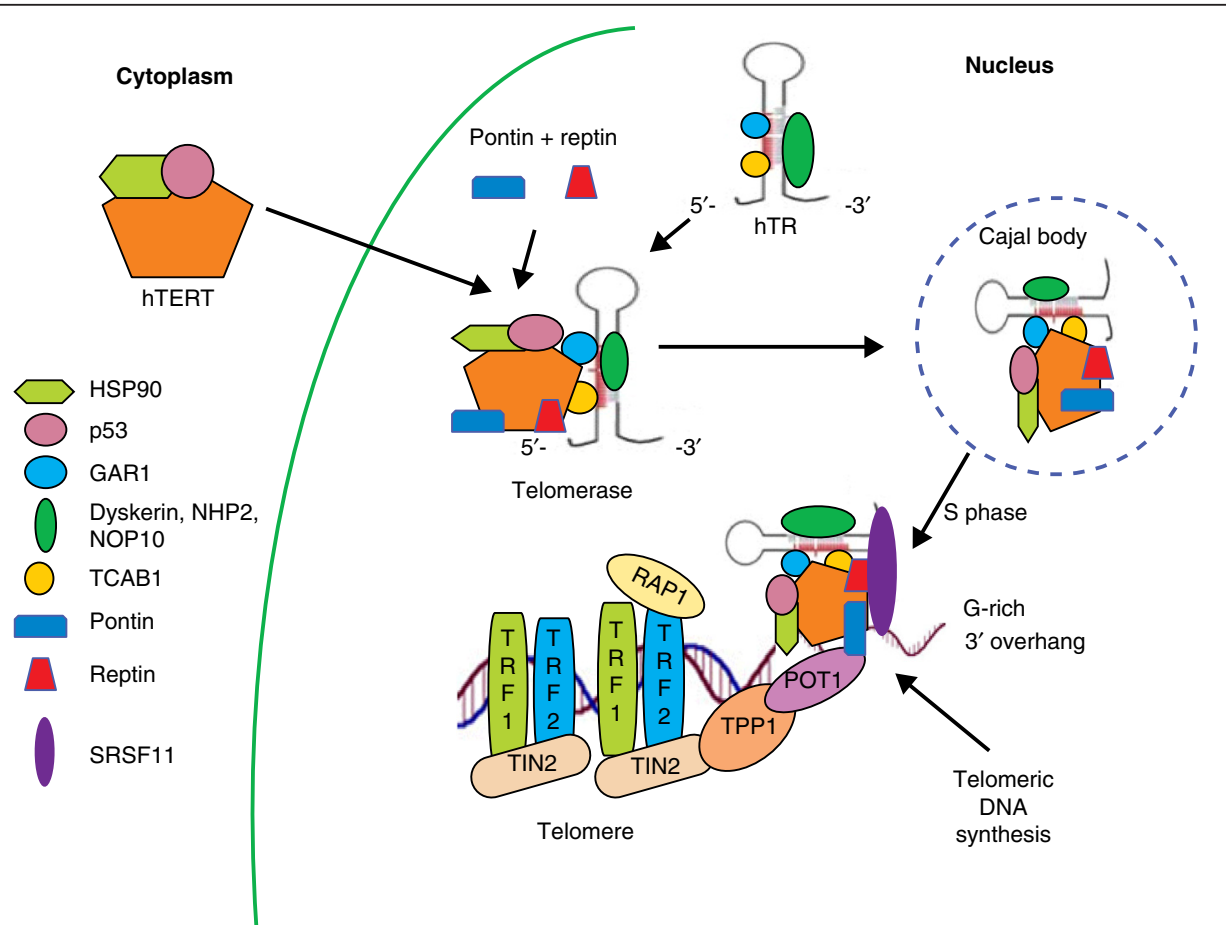

Fig. 3 Telomerase assembly, recruitment to the telomere, and telomeric DNA synthesis. Telomerase is the cellular ribonucleoprotein enzyme complex that catalyzes the extension of telomeric DNA in eukaryotic organisms. Telomerase action involves multiple steps including assembly of the telomerase complex, its intracellular trafficking and finally recruitment to telomeres. Human telomerase is composed of hTR (hTERC - a template functional RNA), hTERT (the catalytic protein component with reverse transcriptase activity), and the accessory proteins dyskerin, NOP10, NHP2, and GAR1. hTERT protein associates with p23 and HSP90 in the cytoplasm, and moves to the nucleus. Nascent hTR transcripts complex with dyskerin, NHP2, NOP10 and GAR1. This complex then undergoes Reptin and Pontin (ATPases)-mediated binding to hTERT + p23 + HSP90 complex. Then TCAB1 attaches to this assembling complex and guides it to Cajal bodies in the nucleus. Telomerase recruitment to telomeres takes place during the $\mathrm{S}$ phase of the cell cycle through interactions between the shelterin complex components TPP1 and POT1 and the DAT domain of hTERT. SRSF11 stabilizes the association of the telomerase enzyme complex with the telomere overhang for DNA synthesis 


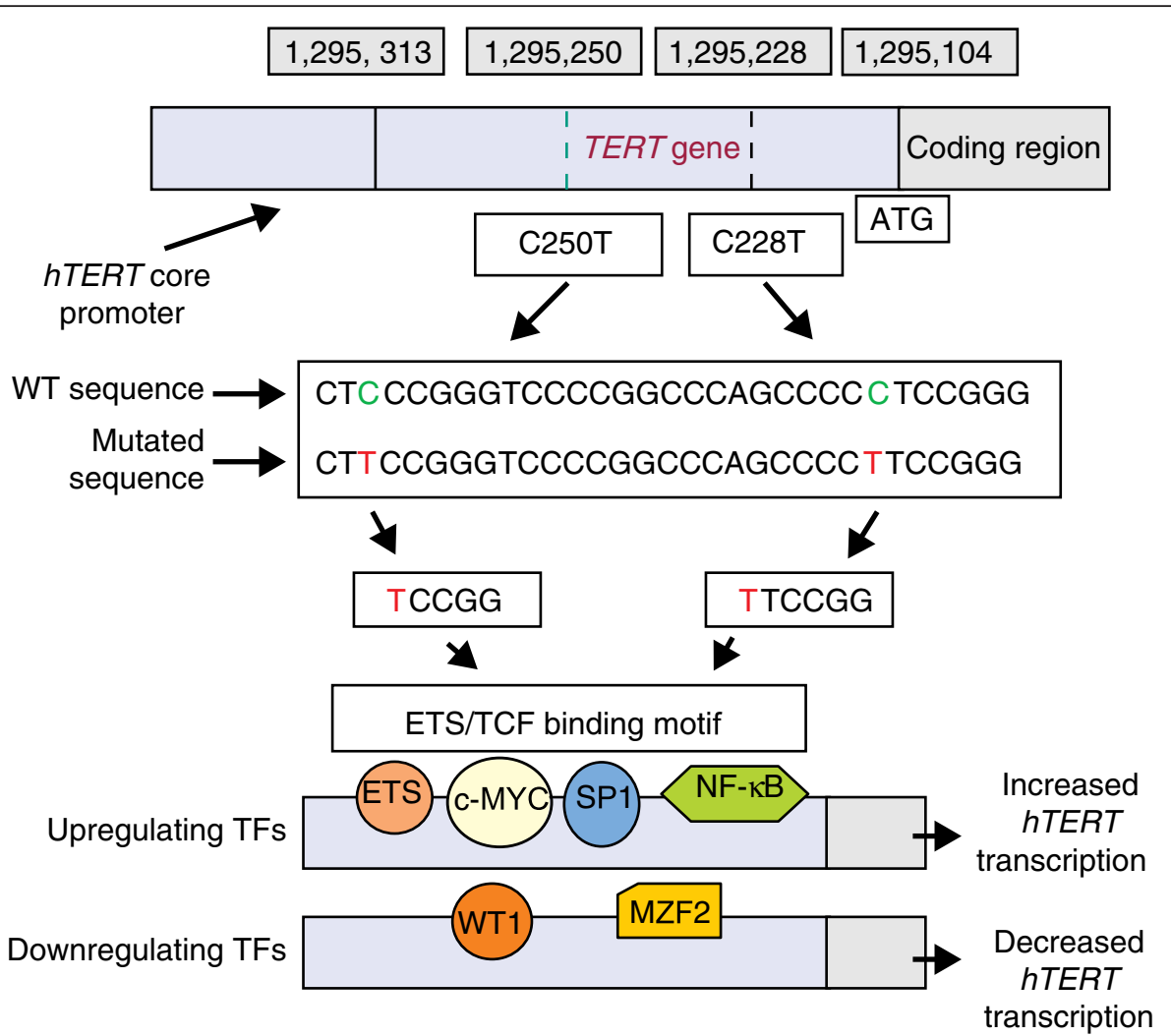

Fig. 4 hTERT transcription and promoter mutations. The hTERT gene is tightly repressed in almost all normal cells and tissues. Specific hTERT promoter mutations as part of cancer progression occur leading to increased transcription of hTERT. The transcription of hTERT is regulated by a series of transcription factors (TFs). hTERT promoter mutations create ETS/TCF binding motifs. Each mutation generates a new ETS/TCF binding site. Upregulating TFs such as ETS, c-MYC, SP1 and NF-kB bind to their respective sites and can promote hTERT transcription. Although binding of TFs is essential for hTERT transcription, in addition a permissive chromatin microenvironment is required. Binding of downregulating transcription factors decreases transcription. WT wild type; WT1 Wilms tumor protein1; MZF2 myeloid zinc finger protein 2

actually related to enhanced telomerase functional enzyme activity and TL maintenance in tumor cells.

While hTERT promoter mutations are frequent in multiple non-epithelial cancer types and their distribution is similar in the majority of patients, Chiba and coworkers [49] have emphasized that the impact of hTERT promoter mutations has mostly been studied in already transformed immortal tumor cells with active telomerase maintaining their telomeres. The tumor cells without such mutations also have sufficient telomerase activity to maintain their telomeres. Therefore, they introduced three common hTERT promoter mutations (-57 A>C, $-124 \mathrm{C}>\mathrm{T},-146 \mathrm{C}>\mathrm{T}$ ) into isogenic human embryonic stem cells (hESCs) using CRISPR/Cas9 genome editing, and observed that in undifferentiated hESCs the presence of -124 C>T caused a 2- to 3-fold increase in hTERT mRNA while neither the $-57 \mathrm{~A}>\mathrm{C}$ nor -146 $\mathrm{C}>\mathrm{T}$ mutation had any effect on $h T E R T$ transcription and none of the three mutations had a major influence on telomerase activity. However, differentiated hESCs (fibroblasts) harboring these mutations continued hTERT transcription (8- to 12 -fold increase) relative to normal hESCs, which would downregulate telomerase activity. Furthermore, telomerase activity in differentiated fibroblasts carrying $h T E R T$ promoter mutations was comparable to that observed in cancer cell lines. Bell and colleagues [50] proposed that GA-binding protein (GABP), an ETS-binding transcription factor, in conjunction with TERT promoter mutations, drives activation of hTERT. They have shown that C228T and C250T transitions are necessary for $h T E R T$ promoter activation, as these generate an ETS motif, which is critically important for the predominant binding of GABP to activate aberrant transcription in cancer cells. However, it is not known whether GABP alone can activate hTERT promoter transcription or if it interacts with other ETSbinding transcription factors. Recently, $\mathrm{Li}$ and coworkers [51] have pointed out that hTERT promoter mutations C228T and C250T are functionally different, in that the $\mathrm{C} 250 \mathrm{~T}$ unlike the $\mathrm{C} 228 \mathrm{~T}$ mutation is regulated by non-canonical NF-kB signaling, which is required for sustained telomerase activity.

While these non-coding hTERT promoter mutations are the most frequent promoter mutations in cancer, the 
level and frequency varies with cancer types (Table 1). Some cancers, such as melanoma, pleomorphic dermal sarcoma, myxoid liposarcoma, glioma, urothelial cell carcinoma, carcinoma of the skin and liver cancer, have the highest frequencies of TERT promoter mutations, while low frequencies were noted in gastric cancer, pancreatic cancer, non-small-cell lung cancer and gastrointestinal stromal tumors $[6,45,48]$. One possible explanation for these observations could be that incipient cancer cells, originating from rapidly self-renewing telomerase-competent cells, do not require TERT promoter mutations to regulate TL maintenance. Thus, cancers arising from these rapidly proliferating cells tend to have less frequent $h T E R T$ promoter mutations and probably just stably upregulate enzyme activity that is reversibly regulated in normal cells. By contrast, cancerinitiating cells originating from cells with low selfrenewing capability may require TERT promoter mutations to overcome the short-telomere-dependent proliferative barrier. However, TERT promoter mutations have not been detected in prostate cancer, a cancer of low self-renewing tissue, suggesting that alterations within the core promoter of the TERT gene do not play an important role in prostate carcinogenesis [52]. The common $h T E R T$ promoter mutations have been detected across all stages and grades in most cancers, suggesting that $h T E R T$ mutations are generally an early event in the process of carcinogenesis [49]. It will be interesting to determine whether these mutations mostly occur during

Table 1 Frequency spectrum of hTERT promoter mutations across diverse cancer types

\begin{tabular}{lll}
\hline Cancer type & $\begin{array}{l}\text { Mutation } \\
\text { frequency (\%) }\end{array}$ & Reference \\
\hline Bladder carcinoma & $47-85$ & {$[100]$} \\
Renal pelvic carcinoma & $60-64$ & {$[101]$} \\
Urothelial carcinoma & 47 & {$[102]$} \\
Hepatocellular carcinoma & $24-59$ & {$[6,103]$} \\
Melanoma & $67-85$ & {$[3]$} \\
Skin basal cell carcinoma & $39-74$ & {$[104]$} \\
Thyroid cancer (papillary and & $50-52$ & {$[105]$} \\
poorly differentiated carcinomas) & & \\
$\begin{array}{l}\text { Myxoid liposarcoma } \\
\text { Glioblastoma }\end{array}$ & $74-79$ & {$[106]$} \\
$\begin{array}{l}\text { Medulloblastoma } \\
\text { Oligoastrocytoma }\end{array}$ & $28-84$ & {$[6,48]$} \\
$\begin{array}{l}\text { Oligodendroglioma } \\
\text { Breast cancer, colorectal cancer, }\end{array}$ & $19-42$ & {$[107]$} \\
medullary thyroid carcinoma, ovarian \\
cancer, esophageal adenocarcinoma, \\
acute myeloid leukemia, chronic lymphoid \\
leukemia, pancreatic cancer, prostate \\
$\begin{array}{l}\text { cancer, testicular carcinoma, uterine } \\
\text { cervix cancer }\end{array}$ & $25-53$ & {$[6,107]$} \\
\hline
\end{tabular}

the period in which cells are undergoing crisis, in order to establish the role of these mutations as early events in the process of malignant transformation.

Telomerase expression also involves transcriptional, post-transcriptional and epigenetic levels of control, which may occur at any critical steps including transcription, mRNA splicing, hTR and hTERT synthesis and maturation, structural organization of telomerase RNP, nuclear localization of telomerase, post-translational modifications, and recruitment to the telomeres [53]. Epigenetic mechanisms such as chromatin remodeling, DNA methylation and histone modifications for regulation of hTERT transcription have also been described $[54,55]$. The expression of $h T E R T$ is also regulated by post-transcriptional mechanisms. The process of gene transcription leads to the generation of transcripts (sequence of pre-mRNA produced by transcription) that are further modified into translational forms by several processes such as mRNA capping (5'-cap), 3 '-polyadenylation and alternative splicing. Alternative splicing of $h T E R T$ mRNA has been shown to be a key post-transcriptional regulatory mechanism [56] but it remains unclear whether telomerase activity is directly associated with $h T E R T$ splicing.

\section{Telomerase as a target for anticancer therapeutics}

Telomerase has been a prime target for the development of effective therapeutics against cancer as it is expressed in the majority of cancer types as well as in cancer stem or stem-like cells. In addition, normal human cells including stem cells have lower telomerase activity and generally maintain telomeres at longer lengths compared to cancer cells. These features provide an advantage that ensures minimum risk for possible telomere shortening in normal cells. The main objective of anti-telomerase therapeutics is to selectively induce apoptosis and cell death in cancer cells while minimizing the effects on normal cells [57]. Multiple approaches have been adopted to achieve this goal through the development of vaccines, antisense oligonucleotides, and small-molecule inhibitors targeting hTERT or hTR. Although the oligonucleotide imetelstat (GRN163L) appears to be the most promising telomerase inhibitor, Bryan and colleagues [58] have reported a novel telomerase inhibitor, BIBR1532, that binds to the thumb domain of TERT, disrupting TERT-RNA binding (telomerase ribonucleoprotein assembly), leading to the inhibition of enzyme activity. However, this compound has not yet progressed to clinical trials. Additionally, development of G-quadruplex stabilizers, tankyrase (which has an important role in telomere homeostasis, mitotic spindle formation and $\mathrm{WNT} / \beta$-catenin signaling) inhibitors and HSP90 (involved in signal transduction, intracellular transport and protein degradation) inhibitors targeting telomere and telomerase assembly, and T-oligo (DNA oligonucleotide homologous to the telomere 3' overhang region, which causes cytotoxic effects 
by inducing DDR) have also been explored to selectively kill cancer cells [59]. In addition, immunotherapies that use dendritic cells (GRVAC1), hTERT peptide (GV1001) or cryptic peptides $(\mathrm{Vx}-001)$ are being tested in clinical trials. Several anti-telomerase agents (imetelstat and vaccines) are currently undergoing different phases of clinical trials but imetelstat is the only anti-telomerase compound that has been extensively evaluated in clinical trials. Recently, the US Food and Drug Administration (FDA) removed a longstanding clinical hold on imetelstat and it is expected to complete planned clinical trials (Table 2).

\section{Developmental highlights of oligonucleotide inhibitor imetelstat}

Imetelstat is a competitive inhibitor of telomerase activity, and was developed for the intravenous treatment of various cancers. It consists of a 13-mer N3'-P5' thiophosphoramidate oligonucleotide that is covalently attached to a palmitoyl (C16 lipid) moiety through a 5'thio-phosphate group (Fig. 5a). The thio-phosphoramidate backbone of imetelstat is responsible for its outstanding features such as high aqueous solubility, acid and metabolic stability, resistance to the action of nucleases, and ability to form RNA duplexes [60]. The lipid moiety of imetelstat provides high lipophilicity that enhances cellular uptake, retention and drug efficacy [61]. Imetelstat does not behave like a typical antisense oligonucleotide as it does not bind to mRNA to inactivate it; rather its sequence (5' -palmitate-TAGGGTTAGACAA- $\mathrm{NH}_{2}-3^{\prime}$ ) binds to a complementary 13-nucleotide region of hTR that has high affinity and specificity at the active site of the telomerase holoenzyme, thus leading to complete inhibition of enzyme activity (Fig. 5b).

Imetelstat has been extensively evaluated for its activity and efficacy against multiple cancer cell lines and in mouse xenograft models in preclinical studies. Imetelstat demonstrated potent inhibitory action against telomerase, causing shortening of telomeres in a large spectrum of cancer cell lines derived from tumors of the bladder, breast, lung, liver, prostrate and pancreas [62-64]. In vivo preclinical studies in mouse models of human tumor xenografts showed that the compound was well tolerated and highly efficacious in inducing telomerase inhibition, leading to reduced tumor growth, prevention of metastasis, and sensitization of tumors to standard chemotherapy [65]. Imetelstat was also found to efficiently prevent glioblastoma tumor growth in a xenograft model by crossing the blood-brain barrier, probably owing to its highly lipophilic nature [66]. Additionally, simultaneous suppression of homologous recombination and telomerase activity in a mouse model of Barrett's adenocarcinoma with the combination of nilotinib (tyrosine kinase inhibitor) and imetelstat was reported to be more effective compared to either compound alone [67].
Imetelstat has been undergoing clinical trials for several years, and while some trials have already been completed, some were discontinued (breast and lung cancer, lymphoproliferative disorders and polycythemia vera) because the US FDA put these on hold due to hematological toxicity, but a few are still continuing (Table 2). Recent clinical development of imetelstat includes two studies, one with patients with myelofibrosis, referred to as the Initial MF Study or the IMbark ${ }^{\mathrm{Tw}}$ study, and one with patients with myelodysplastic syndrome, called the MDS or IMerge ${ }^{\mathrm{mm}}$ study (Table 2). Currently, these studies are recruiting targeted patients at various centers in the USA, Europe and Asia.

\section{Anti-telomerase immunotherapeutics}

Telomerase is an attractive target for the development of telomerase-based immunotherapy. In cancer cells, the degradation of telomerase by proteasomes results in the formation of protein fragments or peptides of telomerase that are expressed on the tumor cell surface as antigens by the human leukocyte antigen (HLA) class I pathway [68, 69], and these telomerase antigenic epitopes can be targeted by cytotoxic $\mathrm{T}$ cells to destroy the tumor cells [70]. Telomerase-specific epitopes can induce $\mathrm{CD} 4^{+}$or $\mathrm{CD} 8^{+}$ cytotoxic T-lymphocyte responses or stimulate antigenpresenting cells capable of attacking tumors [71] (Fig. 6). Therefore, the rationale for anti-telomerase immunotherapy is to sensitize the immune system to tumor cells expressing hTERT peptides to activate and generate hTERTspecific $\mathrm{CD} 8^{+}$cells to produce enhanced anti-tumor effects. Two major strategies have been adopted to develop effective telomerase-based immunotherapy in cancer: an hTERT vaccine approach and a dendritic cell approach to prime antigen-presenting cells ex vivo. Three hTERT vaccines, GV1001, Vx001 and GRNVAC1, have been used to elicit anti-telomerase immune responses in cancer patients [72].

GV1001 is a 16-amino-acid, HLA class II-restricted hTERT peptide that contains amino acid sequence 611626 (EAR-PALLTSRLRFIPK) of the hTERT active site [73]. Granulocyte-monocyte colony-stimulating factor (GM-CSF) or TLR7 is used as adjuvant to carry GV1001. The vaccine is endogenously processed to yield a HLA class I peptide producing both $\mathrm{CD} 4^{+}$and $\mathrm{CD} 8^{+}$responses, thus evoking strong cytotoxic T-lymphocyte activation [74]. Another vaccine called Vx001 is a cryptic peptide (functional peptides hidden in protein structures)-based vaccine containing hTERT amino acid sequence YLFFYRKSV. The vaccine shows high affinity for HLA class I and has demonstrated a significant immune response rate in cancer patients [75, 76]. A dendritic-cell-based vaccine, GRNVAC1, consists of mature autologous dendritic cells transduced with mRNA encoding hTERT and LAMP1. LAMP1 guides hTERT to lysosomes, where it is degraded into small peptides, leading to a polyclonal immune 
Table 2 Completed and ongoing clinical trials of imetelstat in cancer patients

\begin{tabular}{|c|c|c|c|c|c|c|}
\hline $\begin{array}{l}\text { Identifier code/ } \\
\text { phase }\end{array}$ & Indication & Objective & $\begin{array}{l}\text { Start/ } \\
\text { completion date }\end{array}$ & Design & Results & Sponsor \\
\hline $\begin{array}{l}\text { NCT00594126/ } \\
\text { phase I }\end{array}$ & $\begin{array}{l}\text { Refractory or relapsed } \\
\text { multiple myeloma }\end{array}$ & Safety and MTD determination & $\begin{array}{l}\text { November 2007/ } \\
\text { July } 2011\end{array}$ & $\begin{array}{l}3+3 \text { cohort; dose } \\
\text { escalation study }\end{array}$ & $\begin{array}{l}\text { DLT: thrombocytopenia, neutropenia, } \\
\text { anemia, aPTT prolongation, fatigue, } \\
\text { nausea, anorexia and dizziness. }\end{array}$ & Geron \\
\hline $\begin{array}{l}\text { NCT00732056/ } \\
\text { phase I }\end{array}$ & $\begin{array}{l}\text { Recurrent or metastatic } \\
\text { breast cancer }\end{array}$ & $\begin{array}{l}\text { Safety, MTD, efficacy in } \\
\text { combination with paclitaxel } \\
\text { and bevacizumab }\end{array}$ & $\begin{array}{l}\text { July 2008/ } \\
\text { March } 2012\end{array}$ & $\begin{array}{l}3+3 \text { cohort;dose } \\
\text { escalation study }\end{array}$ & DLT: thrombocytopenia, neutropenia. & Geron \\
\hline $\begin{array}{l}\text { NCT00310895/ } \\
\text { phase I }\end{array}$ & Solid tumor malignancies & Safety and MTD determination & $\begin{array}{l}\text { March 2006/ } \\
\text { March } 2013\end{array}$ & $\begin{array}{l}3+3 \text { cohort; } \\
\text { dose escalation study }\end{array}$ & DLT: thrombocytopenia, myelosuppression. & Geron \\
\hline $\begin{array}{l}\text { NCT } 00718601 \\
\text { phase I }\end{array}$ & Multiple myeloma & $\begin{array}{l}\text { Safety and MTD determination } \\
\text { in combination with bortezomib } \\
\text { and dexamethasone }\end{array}$ & $\begin{array}{l}\text { July 2008/ } \\
\text { October } 2011\end{array}$ & $\begin{array}{l}3+3 \text { cohort; dose } \\
\text { escalation study }\end{array}$ & Results not available in public domain. & Geron \\
\hline $\begin{array}{l}\text { NCT00124189/ } \\
\text { phase I }\end{array}$ & $\begin{array}{l}\text { Refractory chronic } \\
\text { lymphoproliferative } \\
\text { disease }\end{array}$ & $\begin{array}{l}\text { Safety, tolerability, dose-limiting } \\
\text { toxicities, and MTD }\end{array}$ & $\begin{array}{l}\text { July 2005/ } \\
\text { March 2013 }\end{array}$ & $\begin{array}{l}\text { Sequential dose cohort, } \\
\text { open label, escalation } \\
\text { trial evaluating one infusion } \\
\text { duration of } 2 \text { h; weekly } \\
\text { intravenous infusion }\end{array}$ & Results not available in public domain. & Geron \\
\hline $\begin{array}{l}\text { NCT00510445/ } \\
\text { phase I }\end{array}$ & $\begin{array}{l}\text { Metastatic non-small- } \\
\text { cell lung cancer }\end{array}$ & $\begin{array}{l}\text { Safety, DLT, MTD in combination } \\
\text { with a standard paclitaxel/carboplatin } \\
\text { regimen }\end{array}$ & $\begin{array}{l}\text { July 2007/ } \\
\text { April } 2011\end{array}$ & $\begin{array}{l}\text { Dose cohorts with a } \\
\text { minimum of } 3 \text { patients }\end{array}$ & $\begin{array}{l}\text { Patients on imetelstat with short TL } \\
\text { showed a trend towards longer median } \\
\text { PFS as well as OS. However, imetelstat } \\
\text { treatment in patients with long TL had } \\
\text { no improvement in median PFS or OS. } \\
\text { ADRs: neutropenia and thrombocytopenia. }\end{array}$ & Geron \\
\hline $\begin{array}{l}\text { NCT01265927/ } \\
\text { phase I }\end{array}$ & HER2 ${ }^{+}$breast cancer & $\begin{array}{l}\mathrm{DLT} \text { in combination } \\
\text { with trastuzumab }\end{array}$ & $\begin{array}{l}\text { January 2011/ } \\
\text { October } 2015\end{array}$ & $\begin{array}{l}\text { Open label, non- } \\
\text { randomized study }\end{array}$ & Results not available in public domain. & Geron \\
\hline $\begin{array}{l}\text { NCT01242930/ } \\
\text { phase II }\end{array}$ & Multiple myeloma & $\begin{array}{l}\text { Improved outcome in patients } \\
\text { previously treated with imetelstat. }\end{array}$ & $\begin{array}{l}\text { November 2010/ } \\
\text { December } 2015\end{array}$ & $\begin{array}{l}\text { Imetelstat } 2 \text { h intravenous } \\
\text { Infusion on day } 1 \text { and day } \\
8 \text { of a } 28 \text {-day cycle }\end{array}$ & Results not available in public domain. & Geron \\
\hline $\begin{array}{l}\text { NCT02598661/ } \\
\text { phase III } \\
\text { IMerge }^{\text {MM }}\end{array}$ & Myelodysplastic syndrome & Safety and efficacy & $\begin{array}{l}\text { November 2015/ } \\
\text { May } 2019\end{array}$ & Randomized, double blind & Recruiting participants. & Janssen \\
\hline $\begin{array}{l}\text { NCT02426086/ } \\
\text { phase II } \\
\text { IMbark study }\end{array}$ & $\begin{array}{l}\text { Myelofibrosis } \\
\text { patients previously } \\
\text { treated with } \\
\text { JAK inhibitor }\end{array}$ & Safety and efficacy & $\begin{array}{l}\text { June 2015/ } \\
\text { March } 2018\end{array}$ & $\begin{array}{l}\text { Randomized, single-blind, } \\
\text { multicenter }\end{array}$ & Recruiting participants. & Janssen \\
\hline $\begin{array}{l}\text { NCT01243073/ } \\
\text { phase II }\end{array}$ & Essential thrombocythemia & Safety and efficacy & $\begin{array}{l}\text { December 2010/ } \\
\text { April } 2015\end{array}$ & Open label, single group & $\begin{array}{l}\text { Eighteen patients, all with positive } \\
\text { hematologic response. Positive } \\
\text { molecular response in most patients } \\
\text { with JAK2 V617F mutation. ADRs: } \\
\text { neutropenia, anemia. }\end{array}$ & Geron \\
\hline $\begin{array}{l}\text { NCT01731951/ } \\
\text { phase II }\end{array}$ & Myelofibrosis & Efficacy & $\begin{array}{l}\text { October 2012/ } \\
\text { January } 2019\end{array}$ & $\begin{array}{l}\text { Open label, parallel, } \\
\text { active, not recruiting }\end{array}$ & $\begin{array}{l}\text { Complete or partial remission in } 21 \% \\
\text { patients. Bone marrow fibrosis was } \\
\text { reversed in a few patients. }\end{array}$ & Janssen \\
\hline
\end{tabular}




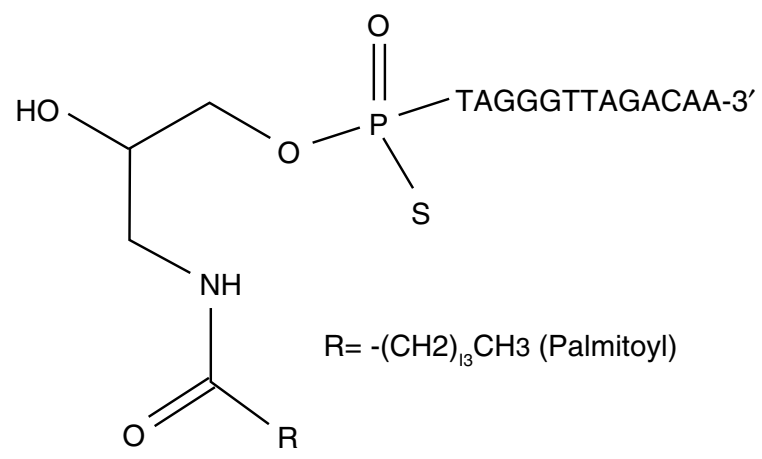

b

hTR

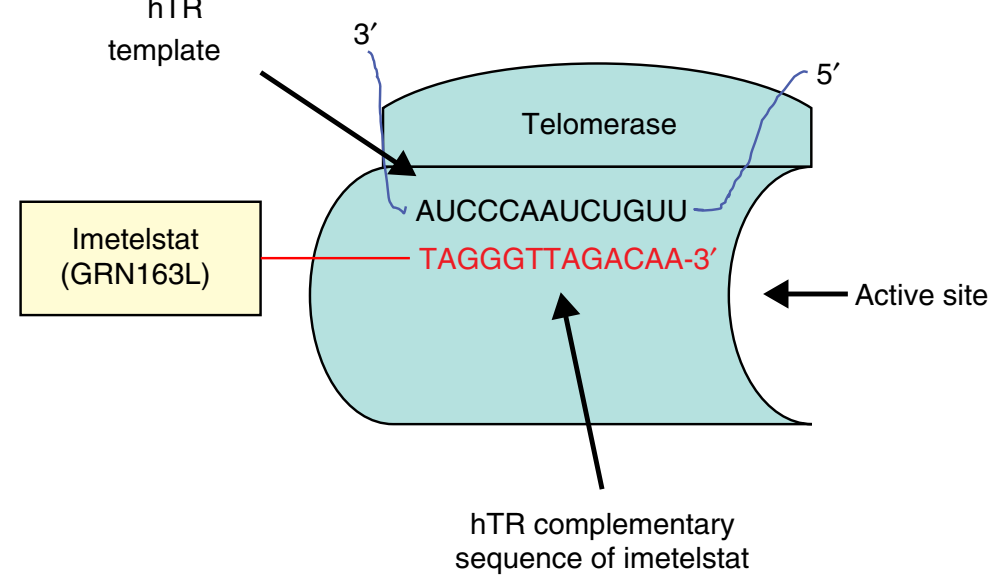

Fig. 5 Structure and action of imetelstat (GRN163L). a Structure of imetelstat. Imetelstat is a lipid-conjugated 13-mer oligonucleotide sequence with a thio-phosphoramidate backbone. The oligonucleotide sequence is complementary to the hTR component of telomerase and is responsible for the inhibitory activity of imetelstat, whereas the thio-phosphoramidate backbone imparts resistance to the action of plasma and cellular nucleases. b Action of imetelstat. Imetelstat binds to the hTR template region at the hTERT active site with high affinity and blocks its recruitment to telomeric DNA. Imetelstat is a competitive telomerase template antagonist (not antisense that targets mRNA). Binding of imetelstat to hTR results in telomerase inhibition leading to progressively shortened telomeres

response specific to all hTERT epitopes expressed by patient tumors [77]. GRNVAC1 was found to be well tolerated with no signs of autoimmunity after three or six weekly injections and elicited robust immune response in patients [78]. Currently, all these vaccines (GV1001, GRNVAC1 and Vx001) are undergoing clinical trials in cancer patients, and the hTERT-specific immune responses elicited by these vaccines were found to be well tolerated in the majority of patients (Table 3).

Clinical trial results have demonstrated that GRNVAC1, Vx001 and GV1001 are promising telomerase-targeting vaccines capable of stimulating $\mathrm{CD} 4^{+}$and $\mathrm{CD} 8^{+}$responses in telomerase-positive tumors, showing minimal effects on normal cells and no autoimmunity. Large multicenter studies are required to determine long-term toxicities in patients. However, at present, it is not certain if any of these vaccine candidates will progress to registration studies to get approval for clinical application.

\section{Exploiting telomerase activity to selectively kill cancer cells}

A major challenge for anti-telomerase-directed therapy is the long lag period required to observe enough TL attrition to induce cell death. Telomere shortening requires a series of cell division cycles to become apparent, and treatment may have to be given continuously for months to induce therapeutically relevant tumor reduction effects. During this treatment period, most tumor cells will continue to grow, which may require the use of other treatment modalities for successful clinical outcomes. Importantly, with direct telomerase inhibitors, if the patient has hematological or any other toxicities (for example, one concern with imetelstat is the development of hematological toxicities requiring drug holidays), then going off treatment for a few weeks would reverse some of the benefits already obtained-the decision about treatment termination or 


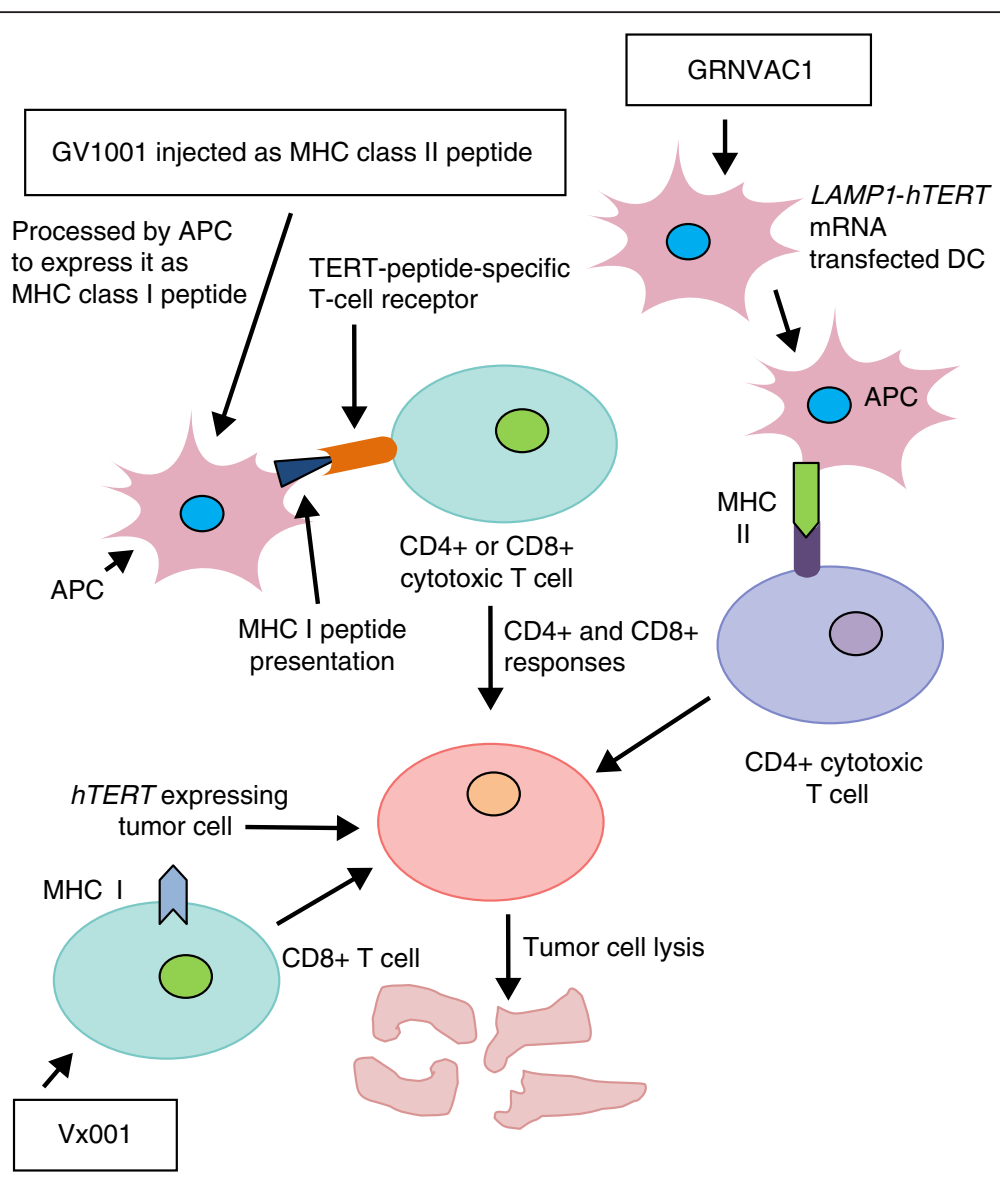

Fig. 6 Anti-telomerase immunotherapy. Several telomerase-based vaccines have been developed, which sensitize immune cells to cancer cells expressing hTERT peptides as surface antigens via the human leukocyte antigen (HLA) class I and class II pathways. This results in an expansion of telomerase-specific $\mathrm{CD} 4^{+}$and $\mathrm{CD} 8^{+}$cytotoxic T lymphocytes (CTLS) in cancer patients leading T cells to target and kill telomerase-positive tumor cells. GV1001 is an MHC class II-restricted hTERT peptide that is further processed by antigen presenting cells (APCs) to present as an MHC class I peptide, and it produces both $\mathrm{CD}^{+}$- and $\mathrm{CD}^{+}$-based immune responses. GRNVAC1 stimulates $\mathrm{CD} 4^{+} \mathrm{T}$ cells to target and kill hTERT-expressing tumor cells. Vx001 action is mediated by $C D 8^{+} \mathrm{T}$ cells

Table 3 Completed and ongoing clinical trials of anti-telomerase vaccines: current status

\begin{tabular}{|c|c|c|c|c|c|}
\hline $\begin{array}{l}\text { Identifier code/ } \\
\text { phase }\end{array}$ & Indication & Objective & $\begin{array}{l}\text { Start/completion } \\
\text { date }\end{array}$ & Results & Sponsor/reference \\
\hline $\begin{array}{l}\text { NCT00510133/ } \\
\text { GRNVAC1 phase II }\end{array}$ & $\begin{array}{l}\text { Acute myelogenous } \\
\text { leukemia }\end{array}$ & Efficacy & $\begin{array}{l}\text { July 2007/August } \\
2014\end{array}$ & $\begin{array}{l}\text { GRNVAC1 was found } \\
\text { to be safe and well } \\
\text { tolerated. } \\
\text { Positive immune responses } \\
\text { in } 55 \% \text { of patients. } \\
\text { Toxicity: thrombocytopenia. }\end{array}$ & $\begin{array}{l}\text { Asterias Biotherapeutics } \\
\text { (http://asteriasbiotherapeutics. } \\
\text { com/pipeline/ast-vac1/) }\end{array}$ \\
\hline $\begin{array}{l}\text { NCT01579188/ } \\
\text { GV1001 phase III }\end{array}$ & $\begin{array}{l}\text { Non-small-cell lung } \\
\text { cancer }\end{array}$ & Efficacy & $\begin{array}{l}\text { May 2012/ } \\
\text { May } 2016\end{array}$ & Ongoing. & Kael-GemVax \\
\hline $\begin{array}{l}\text { NCT00425360/ } \\
\text { GV1001 phase III }\end{array}$ & $\begin{array}{l}\text { Metastatic pancreatic } \\
\text { cancer }\end{array}$ & $\begin{array}{l}\text { Efficacy in combination } \\
\text { with chemotherapy }\end{array}$ & $\begin{array}{l}\text { September 2006/ } \\
\text { March } 2013\end{array}$ & $\begin{array}{l}\text { Adding GV1001 vaccination } \\
\text { to chemotherapy did not } \\
\text { improve overall survival. }\end{array}$ & [108] \\
\hline $\begin{array}{l}\text { NCT01935154/ } \\
\text { Vx001 phase II }\end{array}$ & $\begin{array}{l}\text { Non-small-cell lung } \\
\text { cancer }\end{array}$ & Efficacy & $\begin{array}{l}\text { August 2012/ } \\
\text { December } 2016\end{array}$ & Active. & $\begin{array}{l}\text { Vaxon Biotech (http:// } \\
\text { www.clinicaltrials.gov) }\end{array}$ \\
\hline
\end{tabular}




\section{Box 2. Key outstanding research issues in cancer telomere and telomerase biology}

Determining mechanism(s) of escape from crisis: Cells in crisis undergo tremendous genomic instability due to bridge-fusionbreakage cycles. However, many molecular details remain unclear. What are the molecular features of cells that escape crisis? Do they have hTERT promoter mutations? Why do incipient cancer cells during crisis acquire stem cell-like properties?

hTERT promoter mutations: Some believe that hTERT promoter mutations drive carcinogenesis, while others believe that promoter mutations are only permissive for tumor growth maintenance. How these widespread hTERT promoter mutations regulate $h T E R T$ expression during cellular transformation is not fully understood.

Telomerase holoenzyme assembly: Although there has recently been progress on determining the yeast and ciliate telomerase structure, the processes of assembly and function of telomerase in human cancer cells remain poorly understood.

Recruitment of human telomerase to telomeres in cancer cells: The recruitment of telomerase to telomeres is highly regulated and occurs only after the replication fork remodels protected DNA 3' ends during the S phase of the cell cycle. It involves protein-protein interactions between the shelterin complex components TPP1 and POT1 and the DAT domain of hTERT. TPP1 contains an N-terminal OB-fold domain containing a patch of amino acids termed the Tel patch that directly interacts with the telomerase DAT domain [40]. However, the signaling pathways that regulate telomerase recruitment in human cancer cells are not clearly understood. The telomerase

recruitment process is likely regulated by as yet unknown signaling pathways.

Shelterin protein complex: Emerging evidence suggests a crucial role for shelterin components in cancer progression, but how these components are regulated during different stages of cancer development is not well understood.

Alternative lengthening of telomeres: Recently, knowledge about ALT has increased significantly. The chromatin remodeling factor ATRX acts as a suppressor of ALT in normal cells and mutations in ATRX and DAXX contribute to activation of ALT [28, 91]. However, knockdown of ATRX is not sufficient to trigger the ALT pathway in telomerase-positive cell lines or to directly activate ALT in normal somatic cells, implying the existence of other necessary contributing factors involved in activation of ALT in cancer cells [92, 93]. Thus, many key questions remain

unanswered, such as why ALT is more frequent in certain cancer subtypes? How does ATRX/DAXX repress ALT and what is the molecular basis of its activation in cancer cells with wild-type ATRX/DAXX? What is the function of variant DNA repeats in ALT? How does RAD51

interact with the $5^{\prime}$ overhang of ALT telomeric DNA to facilitate its invasion into homologous DNA, and how are shelterin proteins organized in ALT telomeres?

Answers to these questions may facilitate development of mechanism-based inhibitors for ALT-positive cancers.

stopping treatment for a short duration may depend upon the risk-benefit ratio in terms of efficacy and manifested toxicity.

Therefore, novel fast-acting therapeutic agents that can inhibit telomerase activity would be highly desirable. One such strategy is not to target telomerase directly but to introduce a modified nucleoside into cells so that telomerase would preferentially incorporate it into telomeric DNA. An altered nucleotide incorporated into telomeres would not bind to shelterin proteins efficiently and should lead to telomere dysfunction and rapid cell death. Mender and colleagues [79] have recently demonstrated that, in telomerase-positive cells, 6-thio-2'-deoxyguanosine (6-thio$\mathrm{dG}$ ), a nucleoside analogue of 6-thioguanine (an approved drug), is recognized by telomerase and incorporated into telomeres. This results in altered telomere organization and activation of telomere-associated DNA damage signals called telomere dysfunction-induced foci, and rapid cell death. The nucleoside analogue 6-thio-dG has been evaluated against cell lines and in vivo. Treatment with 6-thio-
dG resulted in rapid cell death, whereas normal telomerase-silent (telomerase-negative) human fibroblasts and normal human colonic epithelial cells were largely unaffected. In in-vivo studies, 6-thio-dG treatment caused significant reduction in tumor growth rates and was superior to 6-thioguanine treatment. Additionally, mice treated with 6-thio-dG at effective doses for a month did not show any hematological, hepatic or renal side effects. Thus, a telomerase-mediated telomere-disrupting approach may provide a safe and efficacious option for the treatment of cancer [80].

\section{Conclusions and future perspectives}

Telomere maintenance has been extensively studied, and our understanding of the role of telomerase and ALT in cancer has improved remarkably in recent years. It is becoming clear how cancer cells regulate different molecular events involved in telomere maintenance to expand their proliferative capacity. Recent insights into the control of telomerase activity at telomeres, through 
Box 3. Telomere biology-based potential novel targets for the development of anticancer agents

Inhibition of the Tel patch to block telomerase recruitment

to telomeres: The "Tel patch", a specific amino acid sequence

in the OB-fold domain of shelterin complex protein TPP1, is

involved in telomerase binding, recruitment, enzyme processivity

and telomere elongation. Thus, inhibition of telomerase

recruitment may result in cell death [94].

Inhibition of telomerase non-canonical function mediators

In addition to telomere maintenance, telomerase may also be

involved in other important activities such as regulating gene

expression, mitochondrial activity, cell proliferation, apoptosis,

epithelial-mesenchymal transitions and DNA damage repair.

These non-canonical putative telomerase functions may be

mediated through a network of "feed forward signaling

loops" [95]. Interventions targeting the molecules involved in

non-telomeric functions of telomerase may be a rational approach

for cancer treatment

Inhibition of TRF1 shelterin protein: TRF1 is overexpressed in many cancer types and plays a central role in controlling replication of telomeric DNA. The genetic abrogation of TRF1

leads to a marked reduction in lung carcinoma tumor growth in the K-Ras ${ }^{G 12 V}$ lung cancer mouse model due to acute telomere uncapping independent of telomere length [96]. However, it is not clear what effects targeting shelterin proteins would have on normal cells.

Inhibition of ATM kinase: The ATM kinase plays a crucial role in the cellular response to telomere dysfunction-mediated DNA damage and subsequent repair pathways. ATM has recently been shown to be required for the addition of telomeric DNA repeats to telomeres and telomere elongation by telomerase in human cells. Blocking ATM inhibits telomere elongation and inhibition of PARP1, which activates ATM and increases telomere elongation [97]. ATM may regulate telomerase access to telomeres through interaction with TRF1 [98].

Inhibition of alternative splicing of mRNA of $h T E R T$ : The human TERT gene produces numerous alternatively spliced variants with a few isoforms capable of producing full-length catalytically active telomerase. A fuller understanding of the process of alternative splicing may lead to the development of molecules to inhibit the generation of full-length telomerase and be a new approach to telomerase therapy in cancer [56]. Inhibition of TERT RNA-binding domain (tTRBD): TERT protein binds to the template boundary element of TR (TERC), crucial for the recognition of the precise telomere sequence to be reverse transcribed by TERT [99]. This is a potential intervention target, but this discovery needs to be established in human cells. telomerase-shelterin interactions, by regulating telomerase recruitment or productive substrate engagement at the enzyme active site, have highlighted opportunities for the development of novel diagnostic tools and effective anticancer agents. Furthermore, recent knowledge gained about the mechanisms underlying the non-canonical functions of telomerase has significantly improved our understanding of the role of telomerase in cancer progression. However, further research efforts are needed to obtain an in-depth understanding of $h T E R T$ activation in the initial stages of carcinogenesis, and the various genetic and epigenetic mechanisms involved in its regulation. While the recurrent $h T E R T$ promoter mutations are highly frequent in many cancers and play a pivotal role in the induction of telomerase reactivation in cancer cells, much remains to be learned about the sufficiency or necessity of $h T E R T$ promoter mutations in cancer initiation and progression. It is still not established whether telomerase expression has any oncogenic characteristics or is simply required for the maintenance of sustained tumor growth (that is, whether it is permissive). Moreover, there are many other unresolved questions regarding telomeres and telomerase function that deserve further investigation (Box 2). Although target-based compounds have greatly benefited patients who have tumors with specific oncogenic mutations, such as EGFR mutation, HER2 amplification, or mutations resulting in ALK expression or KIT expression, the vast majority of common tumors remain less responsive to these target-based drugs. Therefore, novel targeted interventions are required and telomerase inhibition remains a promising strategy for cancer treatment. Recent advances in telomere biology are beginning to unravel potential new telomerase targets (Box 3) for the design of novel molecules targeting the activity of this key enzyme.

Clinical trials with telomerase inhibitors have established telomerase as a viable target, but the time lag between drug administration and clinical response is long. Continued treatment is required for successful clinical outcome, which may lead to severe toxicity in patients. Therefore, a major challenge is to develop a telomerase inhibitor that rapidly kills telomerase-positive tumor cells while sparing normal telomerase-carrying cells.

\section{Abbreviations}

ALT, alternative lengthening of telomeres; bp, base pairs; DAT, dissociates the activities of telomerase; DDR, DNA damage response; FDA, Food and Drug Administration; GM-CSF, granulocyte-monocyte colony-stimulating factor; hESC, human embryonic stem cell; kb, kilobases; OB, oligonucleotide/ oligosaccharide-binding; TERRA, telomeric repeat-containing RNA; T-loop, telomeric loop; TL, telomere length; TPE, telomere position effect; TSS, transcription start site

\section{Acknowledgements}

The laboratory of JWS is supported by the National Cancer Institute (Lung SPORE P50CA70907), RO1AG001228 from the National Institutes of Health, and a distinguished chair from the Southland Financial Foundation in 
Geriatrics Research. This work was performed in laboratories constructed with support from National Institutes of Health grant C06 RR30414.

\section{Authors' contributions}

MAJ wrote manuscript and SAA drew the figures; MHA provided inputs into manuscript writing and JWS edited and finalized the manuscript. All authors read and approved the final manuscript.

\section{Competing interests}

The authors declare that they have no competing interests.

\section{Published online: 20 June 2016}

\section{References}

1. Akincilar SC, Unal B, Tergaonkar V. Reactivation of telomerase in cancer. Cell Mol Life Sci. 2016;73:1659-70.

2. Shay JW. Are short telomeres predictive of advanced cancer? Cancer Discov. 2013:3:1096-8

3. Horn S, Figl A, Rachakonda PS, Fischer C, Sucker A, Gast A, et al. TERT promoter mutations in familial and sporadic melanoma. Science. 2013;339: 959-61.

4. Huang FW, Hodis E, Xu MJ, Kryukov GV, Chin L, Garraway LA. Highly recurrent TERT promoter mutations in human melanoma. Science. 2013;339:957-9.

5. Vinagre J, Almeida A, Popula H, Batista R, Lyra J, Pinto V, et al. Frequency of TERT promoter mutations in human cancers. Nat Commun. 2013:4:2185.

6. Killela PJ, Reitman ZJ, Jiao Y, Bettegowda C, Agrawal N, Diaz LA, et al. TERT promoter mutations occur frequently in gliomas and a subset of tumors derived from cells with low rates of self-renewal. Proc Natl Acad Sci U S A. 2013;110:6021-6.

7. Borah S, Xi L, Zaug AJ, Powell NM, Dancik GM, Cohen SB, et al. TERT promoter mutations and telomerase reactivation in urothelial cancer. Science. 2015;347:1006-10.

8. Picariello L, Grappone C, Polvani S, Galli A. Telomerase activity: an attractive target for cancer therapeutics. World J Pharmacol. 2014;3:86-96.

9. Klewes L, Vallente R, Dupas E, Brand C, Gru D, Guffei A, et al. Three-dimentional nuclear telomere organization in multiple myeloma. Transl Oncol. 2013;6:749-56.

10. Doksani $Y$, Wu JY, de Lange T, Zhuang X. Super-resolution fluorescence imaging of telomeres reveals TRF2-dependent T-loop formation. Cell. 2013;155:345-56.

11. Arnoult N, Karlseder J. Complex interaction between the DNA-damage response and mammalian telomeres. Nat Struct Mol Biol. 2015;22:859-66.

12. Zimmermann M, Kibe T, Kabir S, de Lange T. TRF1 negotiates TTAGGG repeat-associated replication problems by recruiting the BLM helicase and the TPP1/POT1 repressor of ATR signaling. Gene Dev. 2014;28:2477-91.

13. Denchi EL, de Lange T. Protection of telomeres through independent control of ATM and ATR by TRF2 and POT1. Nature. 2007:448:1068-71.

14. Frescas D, de Lange T. TRF2-tethered TIN2 can mediate telomere protection by TPP1/POT1. Mol Cell Biol. 2014;34:1349-62.

15. Frescas $D$, de Lange $T$. Binding of TPP1 protein to TIN2 protein is required for POT1 protein-mediated telomere protection. J Biol Chem. 2014;289:24180-7.

16. Janouskova E, Necasova I, Pavlouskova J, Zimmermann M, Hluchy M, Marini $\checkmark$, et al. Human Rap 1 modulates TRF2 attraction to telomeric DNA. Nucleic Acids Res. 2015:43:2691-700.

17. Pedram M, Sprung CN, Gao Q, Lo AW, Reynolds GE, Murnane JP. Telomere position effect and silencing of transgenes near telomeres in the mouse. Mol Cell Biol. 2006:26:1865-78.

18. Robin JD, Ludlow AT, Batten K, Magdinier F, Stadler G, Wagner KR, et al. Telomere position effect: regulation of gene expression with progressive telomere shortening over long distances. Genes Dev. 2014;28:2464-76.

19. Cusanelli E, Chartrand P. Telomeric repeat-containing RNA TERRA: a noncoding RNA connecting telomere biology to genome integrity. Front Genet. 2015;6:143.

20. Arora R, Lee Y, Wischnewski H, Brun CM, Schwarz T, Azzalin CM. RNaseH1 regulates TERRA-telomeric DNA hybrids and telomere maintenance in ALT tumour cells. Nat Commun. 2014;5:5220.

21. Eid R, Demattei MV, Episkopou H, Auge-Gouillou C, Decottignies A, Grandin N, Charbonneau M. Genetic inactivation of ATRX leads to a decrease in the amount of telomeric cohesin and of telomere transcription in human glioma cells. Mol Cell Biol. 2015;35:2818-30.
22. Bourgeron $T, X u Z$, Doumic M, Teixeira MT. The asymmetry of telomere replication contributes to replicative senescence heterogeneity. Sci Rep. 2015;5:15326.

23. Wright WE, Pereira-Smith OM, Shay JW. Reversible cellular senescence: implications for immortalization of normal human diploid fibroblasts. Mol Cell Biol. 1989;9:3088-92

24. Hayashi MT, Cesare AJ, Rivera T, Karlseder J. Cell death during crisis is mediated by mitotic telomere deprotection. Nature. 2015;522:492-6.

25. Castro-Vega LJ, Jouravleva K, Ortiz-Montero P, Liu WY, Galeano JL, Romero $\mathrm{M}$, et al. The senescent microenvironment promotes the emergence of heterogeneous cancer stem-like cells. Carcinogenesis. 2015;36:1180-92.

26. Shay JW, Wright WE. Role of telomeres and telomerase in cancer. Semin Cancer Biol. 2011;21:349-53.

27. Dilley RL, Greenberg RA. Alternative telomere maintenance and cancer. Trends Cancer. 2015;1:145-56.

28. Napier CE, Huschtscha LI, Harvey A, Bower K, Noble JR, Hendrickson EA, et al. ATRX represses alternative lengthening of telomeres. Oncotarget. 2015;6:16543-58.

29. O'Sullivan RJ, Almouzni G. Assembly of telomeric chromatin to create alternative endings. Trends Cell Biol. 2014;24:675-85.

30. Flynn RL, Cox KE, Jeitany M, Wakimoto H, Bryll AR, Ganem NJ, et al. Alternative lengthening of telomeres renders cancer cells hypersensitive to ATR inhibitors. Science. 2015;347:273-7.

31. Zhang Q, Kim NK, Feigon J. Architecture of human telomerase RNA. Proc Natl Acad Sci U S A. 2011;108:20325-32.

32. Ghosh A, Saginc G, Leow SC, Khattar E, Shin EM, Yan TD, et al. Telomerase directly regulates NF-kB-dependent transcription. Nat Cell Biol. 2012;14:1270-81.

33. Koh CM, Khattar E, Leow SC, Liu CY, Muller J, Ang WX, et al. Telomerase regulates $M Y C$-driven oncogenesis independent of its reverse transcriptase activity. J Clin Invest. 2015;125:2109-22.

34. Liu H, Liu Q, Ge Y, Zhao Q, Zheng X, Zhao Y. hTERT promotes cell adhesion and migration independent of telomerase activity. Sci Rep. 2016;6:22886.

35. Liu Z, Li K, Chen L, Li W, Hou M, Liu T, et al. Telomerase reverse transcriptase promotes epithelial-mesenchymal transition and stem cell-like traits in cancer cells. Oncogene. 2013;32:4203-13.

36. Masutomi K, Kaneko S, Hayashi N, Yamashita T, Shirota Y, Kobayashi K, Murakami S. Telomerase activity reconstituted in vitro with purified human telomerase reverse transcriptase and human telomerase RNA component. J Biol Chem. 2000;275:22568-73.

37. Venteicher AS, Abreu EB, Meng Z, McCann KE, Terns RM, Veenstra TD, et al. A human telomerase holoenzyme protein required for Cajal body localization and telomere synthesis. Science. 2009;323:644-8.

38. Veinteicher AS, Meng Z, Mason PJ, Veenstra TD, Artandi SE. Identification of ATPases pontin and reptin as telomerase components essential for holoenzyme activity. Cell. 2008;132:945-57.

39. Hockemeyer D, Collins K. Control of telomerase action at human telomeres. Nat Struct Mol Biol. 2015;22:848-52.

40. Schmidt JC, Dalby AB, Cech TR. Identification of human TERT elements necessary for telomerase recruitment to telomeres. Elife. 2014;3:e03563.

41. Lee JH, Jeong SA, Khadka P, Hong J, Chung IK. Involvement of SRSF 11 in cell cycle-specific recruitment of telomerase to telomeres at nuclear speckles. Nucleic Acids Res. 2015;43:8435-51.

42. Schmit JC, Cech TR. Human telomerase: biogenesis, trafficking, recruitment and activation. Genes Dev. 2015;29:1095-105.

43. Hsu C, Lee L, Tang S, Hsin I, Lin Y, Ko J. Epidermal growth factor activates telomerase activity by direct binding of Ets-2 to hTERT promoter in lung cancer cells. Tumor Biol. 2015;36:5389-98.

44. Chan AK, Yao Y, Zhenyu Z, Chung NY, Liu JS, Ka-Wai, et al. TERT promoter mutations contribute to subset prognostication of lower-grade gliomas. Modern Pathol. 2015;28:177-86.

45. Huang FW, Bielski CM, Rinne ML, Hahn WC, Seller WR, Stegmeier F, et al. TERT promoter mutations and monoallelic activation of TERT in cancer. Oncogenesis. 2015;4:e176.

46. Heidenreich B, Rachakondan PS, Hemmink K, Kumar R. TERT promoter mutations in cancer development. Curr Opin Genet Dev. 2014;24:30-7.

47. Allory Y, Beukers W, Sagrera A, Flandez M, Marquez M, van der Keur KA, et al. Telomerase reverse transcriptase promoter mutations in bladder cancer: high frequency across stages, detection in urine, and lack of association with outcome. Eur Urol. 2014;65:360-6. 
48. Huang D, Wang Z, Heb XJ, Diplas BH, Yang R, Killela PJ. Recurrent TERT promoter mutations identified in a large-scale study of multiple tumor types are associated with increased TERT expression and telomerase activation. Eur J Cancer. 2015;51:969-76.

49. Chiba K, Johnson JZ, Vogan JM, Wagner T, Boyle JM, Hockemeyer D. Cancer-associated TERT promoter mutations abrogate telomerase silencing. Elife. 2015;4:e7918

50. Bell RJA, Rube HT, Kreig A, Mancini A, Fouse SD, Nagarajan RP, et al. The transcription factor GABP selectively binds and activates the mutant TERT promoter in cancer. Science. 2015;348:1036-9.

51. Li Y, Zhou Q, Sun W, Chandrasekharan P, Cheng H, Ying Z. Non-canonical NF-kB signalling and ETS1/2 cooperatively drive C250T mutant TERT promoter activation. Nat Cell Biol. 2015;17:1327-38.

52. Stoer R, Taubert H, Zinnall U, Giedl J, Gaisa NT, Burger M, et al. Frequency of TERT promoter mutations in prostate cancer. Pathobiology. 2015;82:53-7.

53. Cong YS, Wright WE, Shay JW. Human telomerase and its regulation. Microbiol Mol Biol Rev. 2002;66:407-25.

54. Renaud S, Loukinov D, Abdullaev Z, Guilleret I, Bosman FT, Lobanenkov V, et al. Dual role of DNA methylation inside and outside of CTCF-binding regions in the transcriptional regulation of the telomerase hTERT gene. Nucleic Acids Res. 2007;35:1245-56.

55. Lai SR, Phipps SM, Liu L, Andrews LG, Tollefsbol TO. Epigenetic control of telomerase and modes of telomere maintenance in aging and abnormal systems. Front Biosci. 2005;10:1779-96.

56. Wong MS, Wright WE, Shay JW. Alternative splicing regulation of telomerase: a new paradigm. Trends Genet. 2014;30:430-8.

57. Buseman CM, Wright WE, Shay JW. Is telomerase a viable target in cancer? Mutat Res. 2012;730:90-7.

58. Bryan C, Rice C, Hoffman H, Harkisheimer M, Sweeney M, Skordalakes E. Structural basis of telomerase inhibition by the highly specific BIBR1532. Structure. 2015;23:1934-42

59. Cruz J, Wojdyla L, Ivancich M, Puri N. Targeting the telomere with T-oligo, G-quadruplex stabilizers, and tankyrase inhibitors. J Cancer Sci Ther. 2014;6:10

60. Jackson SR, Zhu CH, Paulson V, Watkins L, Dikmen ZG, Gryaznov SM, et al. Antiadhesive effects of GRN163L-an oligonucleotide N3' $\rightarrow$ P5' thiophosphoramidate targeting telomerase. Cancer Res. 2007;67:1121-9.

61. Herbert BS, Gellert GC, Hochreiter A, Pongracz K, Wright WE, Zielinska D, et al. Lipid modification of GRN163, an N3' $\rightarrow$ P5' thio-phosphoramidate oligonucleotide, enhances the potency of telomerase inhibition. Oncogene. 2005:24:5262-8

62. Marian CO, Wright WE, Shay JW. The effects of telomerase inhibition on prostate tumor-initiating cells. Int J Cancer. 2010;127:321-31.

63. Burchett KM, Yan Y, Ouellette MM. Telomerase inhibitor imetelstat (GRN163L) limits the lifespan of human pancreatic cancer cells. PLoS One. 2014:9:e85155.

64. Hu Y, Bobb D, He J, Hill AD, Dome JS. The HSP90 inhibitor alvespimycin enhances the potency of telomerase inhibition by imetelstat in human osteosarcoma. Cancer Biol Ther. 2015;16:949-57.

65. Dikmen ZG, Gellert GC, Jackson SR, Gryaznov SM, Tressler R, Dogan P, et al. In vivo inhibition of lung cancer by GRN163L: a novel telomerase inhibitor. Cancer Res. 2005;65:7866-73.

66. Marian CO, Cho SK, McEllin BM, Maher EA, Hatanpaa KJ, Madden CJ, et al. The telomerase antagonist, imetelstat, efficiently targets glioblastoma tumor-initiating cells leading to decreased proliferation and tumor growth. Clin Cancer Res. 2010;16154-63.

67. Lu R, Pal J, Buon L, Nanjappa P, Shi J, Fulciniti M, et al. Targeting homologous recombination and telomerase in Barrett's adenocarcinoma: impact on telomere maintenance, genomic instability and tumor growth. Oncogene. 2014;33:1495-505.

68. Vonderheide RH, Hahn WC, Schultze JL, Nadler LM. The telomerase catalytic subunit is a widely expressed tumor-associated antigen recognized by cytotoxic T lymphocytes. Immunity. 1999;10:673-9.

69. Lev A, Denkberg G, Cohen CJ, Tzukerman M, Skorecki KL, Chames P, et al. Isolation and characterization of human recombinant antibodies endowed with the antigen-specific, major histocompatibility complexrestricted specificity of $\mathrm{T}$ cells directed toward the widely expressed tumor T-cell epitopes of the telomerase catalytic subunit. Cancer Res. 2002;62:3184-94.

70. Vonderheide $\mathrm{RH}$. Telomerase as a universal tumor-associated antigen for cancer immunotherapy. Oncogene. 2002;21:674-9.

71. Vonderheide $\mathrm{RH}$. Prospects and challenges of building a cancer vaccine targeting telomerase. Biochimie. 2008;90:173-80.
72. Ruden M, Puri N. Novel anticancer therapeutics targeting telomerase. Cancer Treat Rev. 2013;39:444-56.

73. Kyte JA. Cancer vaccination with telomerase peptide. Expert Opin Investig Drugs. 2009;18:687-94.

74. Brunsvig PF, Aamdal S, Gjertsen MK, Kvalheim G, Markowski-grimsrud CJ, Sve I, et al. Telomerase peptide vaccination: a phase I/II study in patients with non-small cell lung cancer. Cancer Immunol Immunother. 2006;55:1553-64.

75. Georgoulias V, Douillard JY, Khayat D, Manegold C, Rosell A, Menez-Jamet J, et al. A multicenter randomized phase IIb efficacy study of $V x-001$, a peptidebased cancer vaccine as maintenance treatment in advanced non-small-cell lung cancer: treatment rationale and protocol dynamics. Clin Lung Cancer. 2013:14:461-6.

76. Kotsakis A, Papadimitraki E, Vetsika EK, Aggouraki D, Dermitzaki EK, Hatzidaki $D$, et al. A phase II trial evaluating the clinical and immunologic response of $\mathrm{HLA}-\mathrm{A} 2^{+}$non-small cell lung cancer patients vaccinated with an hTERT cryptic peptide. Lung Cancer. 2014;86:59-66.

77. Ouellette MM, Wright WE, Shay JW. Targeting telomerase-expressing cancer cells. J Cell Mol Med. 2011;15:1433-42.

78. Su Z, Dannull J, Yang BK, Dahm P, Coleman D, Yancey D, et al. Telomerase mRNA-transfected dendritic cells stimulate antigen-specific $\mathrm{CD}^{+}$and $\mathrm{CD}^{+}$ T cell responses in patients with metastatic prostate cancer. J Immunol. 2005;174:3798-807.

79. Mender I, Gryaznov S, Dikmen ZG, Wright WE, Shay JW. Induction of telomere dysfunction mediated by the telomerase substrate precursor 6thio-2'-deoxyguanosine. Cancer Discov. 2015;5:82-95.

80. Mender I, Gryaznov S, Shay JW. A novel telomerase substrate precursor rapidly induces telomere dysfunction in telomerase positive cancer cells but not in telomerase silent normal cells. Oncoscience. 2015;2:693-5.

81. Muller HJ. The remaking of chromosomes. Collecting Net. 1938;13:181-98.

82. McClintock B. The stability of broken ends of chromosomes in Zea mays. Genetics. 1941;26:234-82

83. Hayflick L, Moorhead PS. The serial cultivation of human diploid cell strains. Exp Cell Res. 1961;25:585-621.

84. Watson JD. Origin of concatemeric T7 DNA. Nat New Biol. 1972;239:197-201.

85. Olovnikov AM. A theory of marginotomy. The incomplete copying of template margin in enzymic synthesis of polynucleotides and biological significance of the phenomenon. J Theor Biol. 1973;41:181-90.

86. Blackburn EH, Gall JG. A tandemly repeated sequence at the termini of the extrachromosomal ribosomal RNA genes in Tetrahymena. J Mol Biol. 1978; 120:33-53.

87. Greider CW, Blackburn EH. Identification of a specific telomere terminal transferase activity in Tetrahymena extracts. Cell. 1985;43:405-13.

88. Morin GB. The human telomere terminal transferase enzyme is a ribonucleoprotein that synthesizes TTAGGG repeats. Cell. 1989;59:521-9.

89. Kim NW, Piatyszek MA, Prowse KR, Harley CB, West MD, Ho PL, et al. Specific association of human telomerase activity with immortal cells and cancer. Science. 1994:266:2011-5.

90. Bodnar AG, Ouellete M, Frolkis M, Holt SE, Chiu C-P, Morin GB, et al. Extension of lifespan by introduction of telomerase in normal human cells. Science. 1998;279:349-52.

91. Clynes D, Jelinska C, Xella B, Ayyub H, Scott C, Mitson M, et al. Suppression of the alternative lengthening of telomere pathway by the chromatin remodelling factor ATRX. Nat Commun. 2015;6:7538.

92. Heaphy CM, de Wilde RF, Jiao Y, Klein AP, Edil BH, Shi C, et al. Altered telomeres in tumors with ATRX and DAXX mutations. Science. 2011;333:425.

93. Bower K, Napier CE, Cole SL, Dagg RA, Lau LMS, Duncan EL, et al. Loss of wild-type ATRX expression in somatic cell hybrids segregates with activation of alternative lengthening of telomeres. PLoS One. 2012;7:e50062.

94. Nakashima M, Nandkumar J, Sullivan KD, Espinosa JM, Cech TR. Inhibition of telomerase recruitment and cancer cell death. J Biol Chem. 2013;288:33171-80.

95. Li Y, Tergaonkar $V$. Noncanonical functions of telomerase: implications in telomerase-targeted cancer therapies. Cancer Res. 2014;74:1639-44.

96. Garcia-Beccaria M, Martinez P, Mendez-Pertuz M, Martinez S, Blanco-Aparicio C, Canamero M. Therapeutic inhibition of TRF1 impairs the growth of p53deficient K-Ras ${ }^{G 12 \mathrm{~V}}$-induced lung cancer by induction of telomeric DNA damage. EMBO Mol Med. 2015;7:930-49.

97. Lee SS, Bohrson C, Pike AM, Wheelan SJ, Greider CW. ATM kinase is required for telomere elongation in mouse and human cells. Cell Rep. $2015 ; 13: 1623-32$ 
98. Tong AS, Stern JL, Sfeir A, Kartawinata M, de Lange T, Zhu XD, et al. ATM and ATR signaling regulate the recruitment of human telomerase to telomeres. Cell Rep. 2015;13:1633-46.

99. Jansson LI, Akiyama BM, Ooms A, Lu C, Rubin SM, Stone MD. Structural basis of template-boundary definition in Tetrahymena telomerase. Nat Struct Mol Biol. 2015;22:883-8.

100. Rachkonda PS, Hosen I, de Verdier PJ, Fallah M, Heideneich B, Ryk C, et al. TERT promoter mutations in bladder cancer affect patient survival and disease recurrence through modification by a common polymorphism. Proc Natl Acad Sci U S A. 2013;110:17426-31.

101. Wang K, Liu T, Liu L, Liu J, Liu C, Wang C, et al. TERT promoter mutations in renal cell carcinoma and upper tract urothelial carcinomas. Oncotarget. 2014;5:1829-36

102. Wang K, Liu T, Ge N, Liu L, Yuan X, Liu J, et al. TERT promoter mutations are associated with distant metastases in upper tract urothelial carcinomas and serve as urinary biomarkers detected by a sensitive castPCR. Oncotarget. 2014:5:12428-39.

103. Cevlik D, Yildiz G, Ozturk M. Common telomerase reverse transcriptase promoter mutations in hepatocellular carcinomas from different geographical locations. World J Gastroenterol. 2015;21:311-17.

104. Vinagre J, Pinto V, Celestino R, Reis M, Populo H, Boaventura P, et al. Telomerase promoter mutations in cancer: an emerging molecular biomarker? Virchows Arch. 2014;465:119-33.

105. Liu X, Bishop J, Shan Y, Pai S, Liu D, Murugan AK, et al. Highly prevalent TERT promoter mutations in aggressive thyroid cancers. Endocr Relat Cancer. 2013;20:603-10.

106. Koelsche C, Renner M, Hartmann W, Brandt R, Lehner B, Waldburger N, et al. TERT promoter hotspot mutations are recurrent in myxoid liposarcomas but rare in other soft tissue sarcoma entities. J Exp Clin Cancer Res. 2014;33:33.

107. Koelsche C, Sahm F, Capper D, Reuss D, Stum D, Jones DT, et al.

Distribution of TERT promoter mutations in pediatric and adult tumors of the nervous system. Acta Neuropathol. 2013;126:907-15.

108. Middleton G, Silcocks P, Cox T, Valle J, Wadsley J, Propper D, et al. Gemcitabine and capecitabine with or without telomerase peptide vaccine GV1001 in patients with locally advanced or metastatic pancreatic cancer: an open-label, randomised, phase 3 trial. Lancet Oncol. 2014;15:829-40. 